القدرة التنافسية للصادرات المصرية من البصل فى أهم الأسواق العالمية

\title{
وتوقعاتها المستقبلية
}

\author{
عماد الدين الثربينى
}

dr_emad222@yahoo.com

معهد بحوث الاقتصاد الززاعى

Received: Feb. 18, 2018

Accepted: Apr. 17, 2018

الملخص

يتناول البحث قياس أهم العوامل المؤثرة على الطلب الذارجي للبصل المصري في أهم الأسواق العالمية من خلال التقلير القياسى لمحددات الطلب الخارجى على صادلات البصل المصي فى أهم الأسواق العالمية خلال متوسط الفترة (2016-2000). كما بتناول البحث حساب بعض مقابيس القدة التتافسية لمحصول البصل المصري (مؤثر النصيب

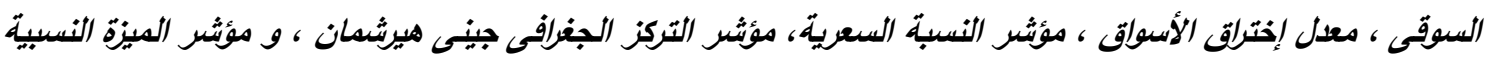

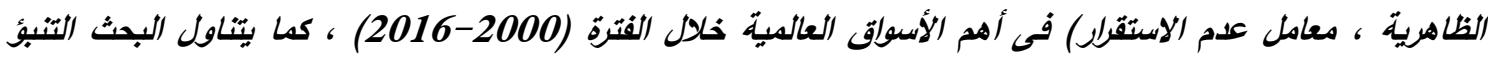
بقيمة وكمية صادلات محصول البصل حتى عام 2020 من خلال تصلي أفضل الأساليب القياسية المستخدمة في التتبؤ

بإستخد/م نموذج بوكس -جينكيز " Box-Jenkins ".

وقد أوضحت نتائج تقلير دالة الطلب الذارجى على صادلات البصل المصري فى أهم الأسواق العالمية وجول علاقةت

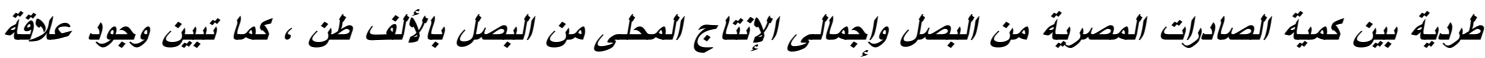

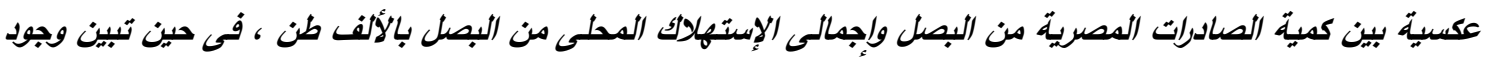
علاقة عكسية بين كمية الصادلات المصرية من البصل وسعر التصدير من البصل المصرى بالدولار/طن ، فى حين تبين وجود علاقة طردية بين كمية الصادرات المصرية من البصل وسعر التصدير من البصل الهندى بالدولار/طن. وقد تبين من خلال النتائج التي أسفرت عنها الدراستة:

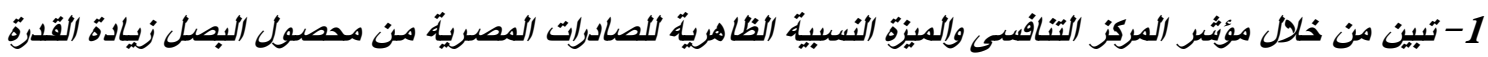
التنافسية لمحصول البصل في الأسواق الذارجية خلال فترة الداسية.

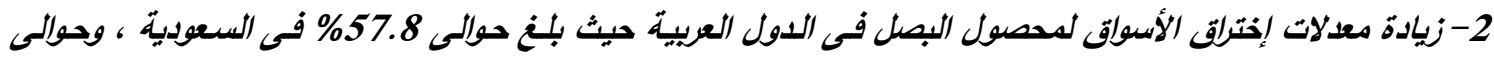

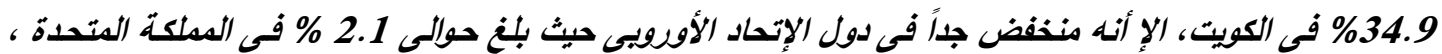

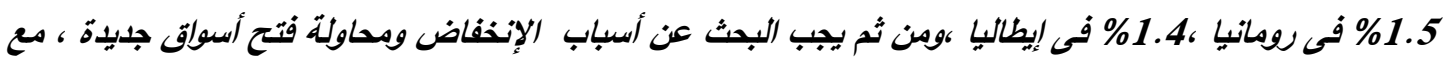
ضروة الاستفادة من تجارب الدول المنافسة فى تصدير ذلك المحصول. 3- ضرورة توافر البيانات الكافية أمام المصدرين عن السوق الذارجى ، وتثجيع الدراسات التسى تقوم على دراستة الطلب الذارجي على الصادرات النزاعية لأهم المحاصيل التصديرية المصرية. 4- تبين من خلال التقلير القياسى لاوال الطلب على البصل المصرى فى أهم الأسواق الذارجية خلال الفترة (2000-

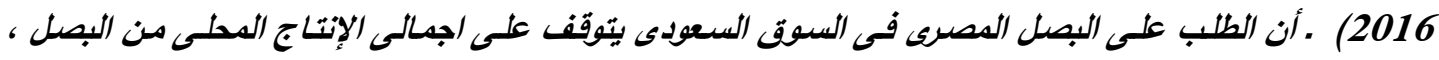

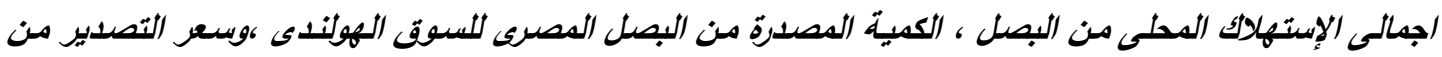

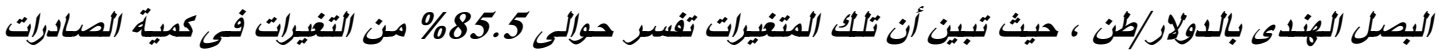




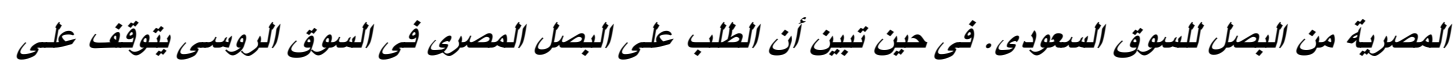

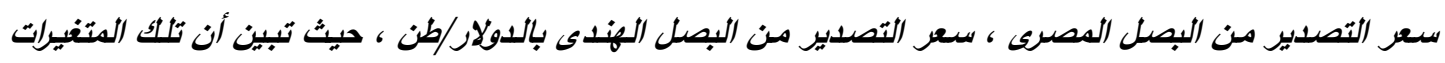

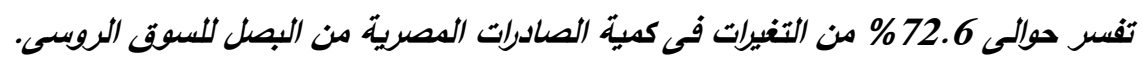

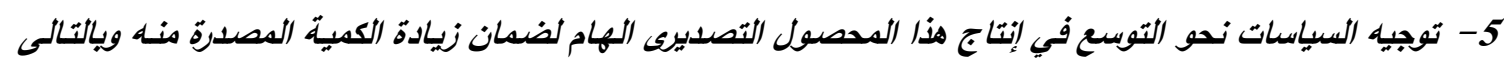
زبيادة قيمة الصادرات

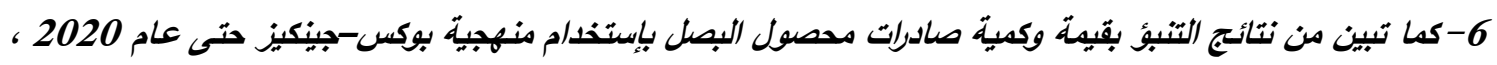

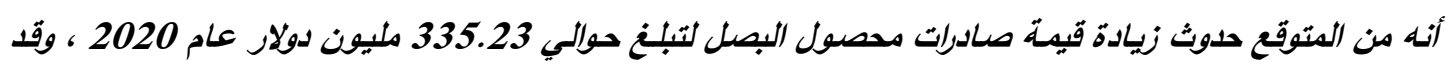

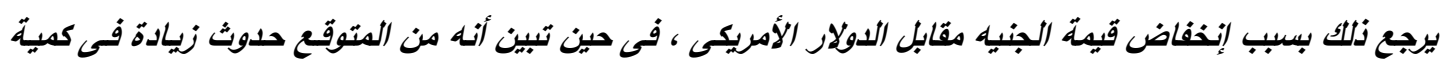
صادلات محصول البصل لتبلغ حوالي 568.68 ألف طن عام 2020.

الكلمات الإسترشادية: القلدة التنافية ، مؤشر النصيب السوقى ، معدل إخترلق الأسواق ، مؤثر النسبة السعرية، مؤثر

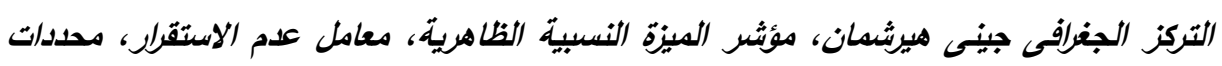

الطلب الخارجى، التنبؤ، نموذج الأرييا.

حوالى 53.2\%، كما إنخفضت الصـادرات الزراعية مـن

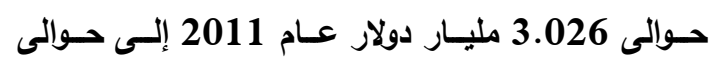

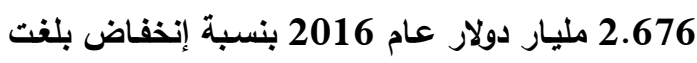
حوالى 11.6 \% من عام 2011 ، حيث إنخفض العجز فى الميزان التجاري الزراعي من حوالى 11.185 ملئ عليار

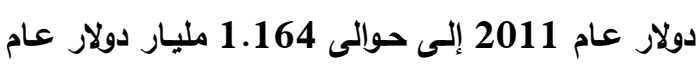

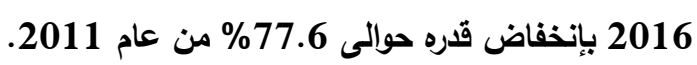

\section{المشكلة البحثية :}

بالرغم من أهمية الصادرات فى توفير النق الأجنبى

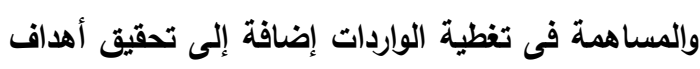
التنمية ، الإ أن معدل تغطية الصادرات الكلية للواردات الكلية قد بلغ حوالى 45.4 \% خلال متوسط الفترة (2016-2000) ، حيث إنخفضت الصادرات المصرية

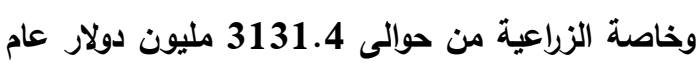
2010 إلى حوالى 2675.9 مليون دولار عام 2016 بنسبة إنخفاض بلغت حوالى 14.5 \% من عام 2010.

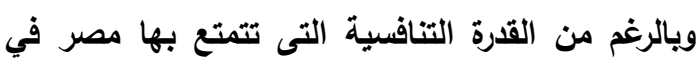
إنتاج وتصدير البصل ، حيث بلغت المساحة المزروعة به حوالى 154 ألف فدان عام 2016 ، الإ أن إجمالي

تلعب التجـارة الخارجيـة فـي ظل العولمــة وتحريـر

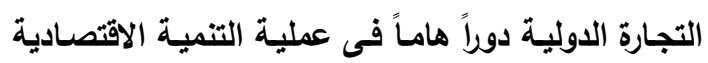

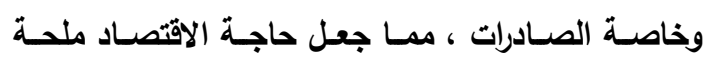

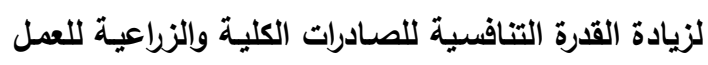

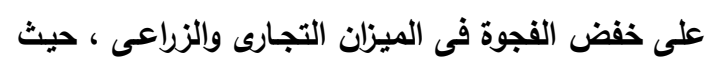
زادت الواردات الكليـة مـن حوالى فئل 62.223 مليـار دولار

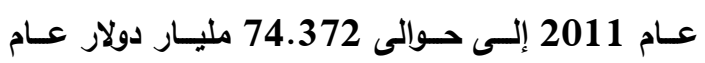
2015 بنسبة زيادة بلغت حوالى 19.52\% على 19.73 ، الإ أنها إنخفضت عام 2016 لتبلغ حوالى 59.73 مليار دولار

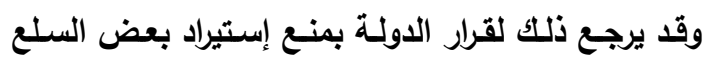

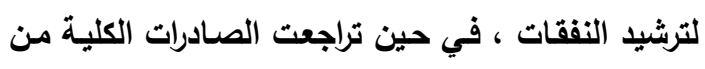

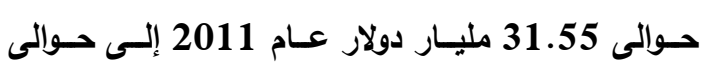
22.122 مليار دولار عام 2016 بنسبة إنخفاض بلغت حوالى 29.9 \% مسن عسام 2011 ، كمسا تبين زيـادة

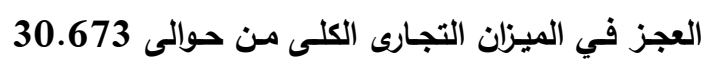

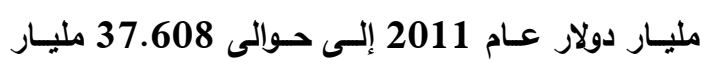

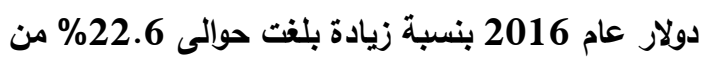
عام 2011 .فى حين إنخفضت قيمة الواردات الزراعية

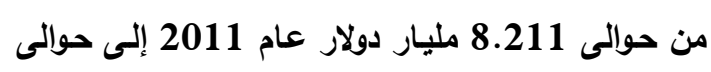
3.840 مليار دولار عام 2016 بنسبة إنخفاض بلغت 
5- التتبؤ بقيمة وكمية الصادرات المصرية من البصل حتى عام 2020. الإسلوب البحثي و مصادر البيانات:

إعتمد هذا البحث فى تحقيق أهدافه على أسلويى التحليل الاحصائى الوصفى والكمى ، حيث تم إستخدام بعض الأساليب التحليلية الإحصائية، كتحليل السلاسل الزمنية ، وأسلوب الإنحدار المرطى Stepwise ، حيث تم إستخدام اسلوب الإنحدار البسيط فى دراسة تطور متغيرات الدراسة والإنحار المتعدد فى التعرف على لإنى محدات الطلب الخارجى للبصل المصرى فى أهم الأسواق الاولية وقد تم تحديد النماذج المذكورة فى أكثر من صورة، وقد تمت المفاضلة بين تلك النماذج وإختيار أفضلها بحيث تتفق مع المنطق الإقتصادى والإحصائى من حيث قيمة R², t, F ، ولتقدير القدرة التنافسية لمحصول البصل فى أهم الأسواق العالمية فق تم استخدام بعض مقاييس القدرة التتافسية مثل (مؤثر الفرول النصيب السوقى ، معدل إختراق الأسواق ، مؤثشر النسبة

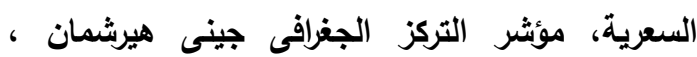
ومعامل عدم الاستقرار لكمية الصادرات المصرية من Box-Jenkins Bمل، كما تم إستخدام نماذج فى التبؤ بكمية وقيمة الصادرات المصرية من البصل، وهى نماذج تعتمد على إستخلاص المتوسط الحسابى للمتغير كنماذج للتنبؤ المستقبلى، ولكن بعد

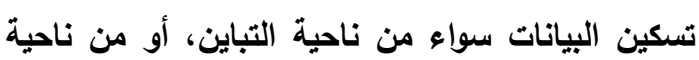
الإتجاهية، ثم تقدير البواقى (الخطأ العثوائى) بأسلوب الإنحدار الذاتى مع المتوسط المتحرك، كما فى المعادلة

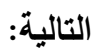

الكميات المصدرة للبصل قد تراجعت من حوالى 1219.07 ألف طن عام 2015 إلى حوالى 515.03 ألف طن عام 2016 بنسبة إنخفاض بلغت حوالى 57.8 من عام 2015، وتراجعت قيمة صادرات البصل من حوالى 263.5 مليون دولار عام 2015 إلى حوالى 193.9 مليون دولار عام 2016 بنسبة إنخفاض بلغت حوالى 26.4\% من عام 2015، الأمر الذى إستدعى ضرورة دراسة أهم محددات زيادة الطلب على منى البصل المصري فى الأسواق العالمية. الأهداف البحثية:

تستهدف هذه الاراسة القدرة التنافسية للصادرات المصرية من البصل المصري في أهم الأسواق العالمية من خلال دراسة الأهداف الفرعية الآتية : 1- الوضع الراهن للصادرات المصرية من محصول البصل خلال متوسط الفترة (2000-2016). 2- التوزيع الجغرافى للصادرات المصرية من البصل لأهم الاول المستوردة خلال متوسط الفترة (2000(2016 3- حساب بعض مقاييس القدرة التنافسية لمحصول البصل المصري (مؤثثر النصيب السوقى ، معدل

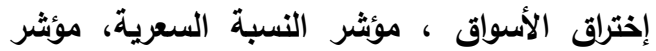
التركز الجغرافى جينى هيرشمان ، و مؤثر الميزة

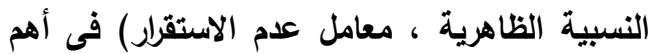
الأسواق العالمية خلال الفترة (2000-2016). 4- التقدير القياسى لدالة محدات الطلب على صادرات البصل المصري فى أهم الأسواق العالمية خلال متوسط الفترة (2000-2016).

$$
\mathrm{Y}_{\mathrm{it}}=\beta_{0}+\beta_{1} \mathrm{Y}_{\mathrm{it}-1}+\beta_{2} \mathrm{Y}_{\mathrm{it}-2}+--------------+\beta_{\rho} \mathrm{Y}_{\mathrm{it}-\rho}+\varepsilon_{\mathrm{i}}+\theta_{1} \varepsilon_{\mathrm{it}-1}+\theta_{2} \varepsilon_{\mathrm{it}-2}+----+\boldsymbol{\theta} \varepsilon_{\mathrm{it}-\mathrm{q}}
$$


أما بالنسبة للميزان التجارى الإجمالى فيتضح من دراسة بيانات ملحق (1) وجود عجز دائم فى الميزان

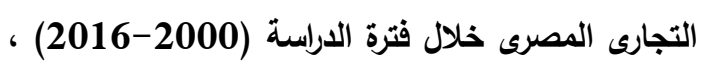
قدر حده الأدنى بنحو 4736 مليون دولار عام 2003 وحده الأقصى بنحو 53032 مليون دولار عام 2015

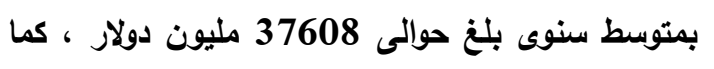
يتضح من المعادلة رقم (3) أن العجز في الميزان

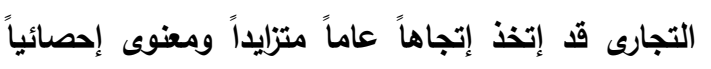

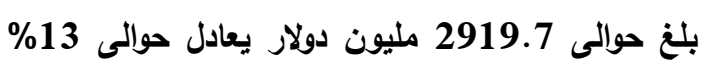
من متوسطه السنوى خلال فترة الاراسة.

2- الوضع الراهن لتطور مؤشرات التجارة الخارجية الزراعية:

يتضح من دراسة الجدول رقم (1) أن قيمة الصادرات

الزراعية قد تراوحت بين حد أدنى بلغ حوالى 508.7

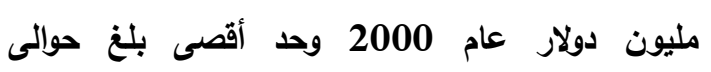
3131.4 مليون دولار عام 2010 وقدر المتوسط السنوى لقيمة الصادرات الزراعية حوالى دام 1871.4

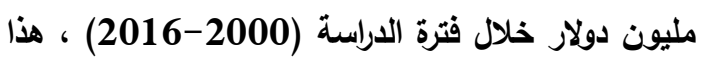

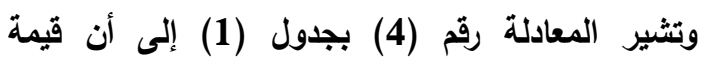

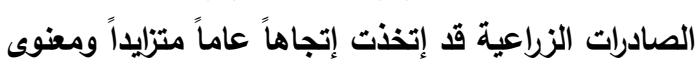

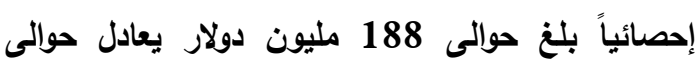
10 من متوسطها السنوى البالغ حوالى 1871.4 مليون دولار.

أما بالنسبة للواردات الزراعية فقد تراوحت بين حد أدنى بلغ حوالى 1705.4 مليون دولار عام 2004 وحد أقصى بلغ حوالى 8805.5 مليون دولار عام 2012

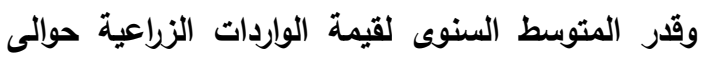
3932 مليون دولار خلال فترة الاراسة (20002016) ، ويتضح من المعادلة رقم (5) إلى أن قيمة فلان

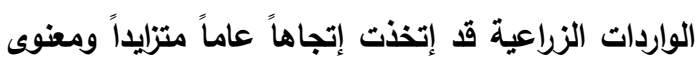

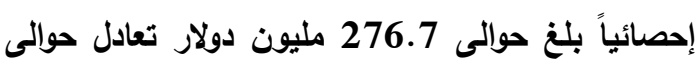
\% من متوسطها السنوى خلال فترة الدراسة.
وقد اعتمدت الدراسة على البيانات الثانويـة المنثورة

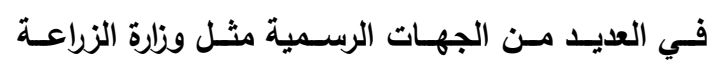
وإستصلاح الأراضس، ونثرات التجارة الخارجية الصـادرة

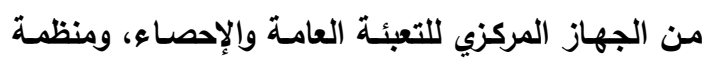
الأغذيـة والزراعـة العالميـة (FAO) ، كمـا تـم الإستعانة ببعض الأبحاث والرسائل والاراسات والكتب العلمية التي لها صلة بموضوع البحث.

مناقشة النتائج أولاً: الوضع الراهن لتطور مؤثرات التجارة الخارجية

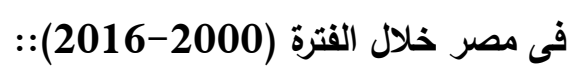
1- الوضع الراهن لتظور مؤشرات التجارة الخارجية الكلية: يتضح من دراسة الجدول رقم (1) أن قيمة الصادرات الكلية قد تزاوحت بين حد أدنى بلغ حوالى 4143 مليون دولار عام 2001 وحد أقصى بلغ حوالى 31550 مليون دولار عام 2011 وقدر المتوسط السنوى لقيمة الصادرات الكلية حوالى 18014 مليون دولار خلال فترة الاراسة (2000-2016) ، هذا وتثثير المعادلة رقم (1) بجدول (1) إلى أن قيمة الصادرات الكلية قد إتخذت التهائ

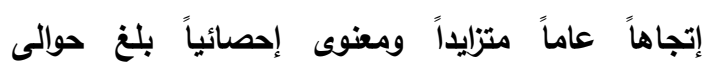

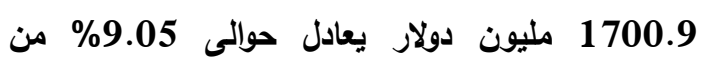
متوسطها السنوى البالغ حوالى 18014.1 مليون

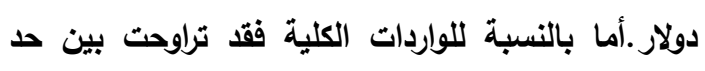

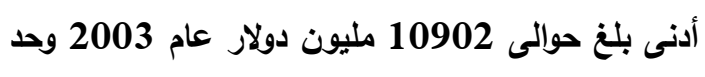
أقصى بلغ حوالى 74372 مليون دولار عام 2015 وقدر المتوسط السنوى لقيمة الواردات الكلية حوالى دلى دلى 40511 مليون دولار خلال فترة الدراسة (20002016) ، ويتضح من المعادلة رقم (20511 إلى أن قيمة

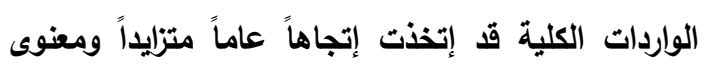
إحصائياً بلغ حوالى 4620.7 مليون دولار تعادل حوالى 11.4 من متوسطها السنوى خلال فترة الاراسة. 
جدول (1) : معدلات الإتجاه الزمنى العام لمتغيرات الدراسة خلال الفترة (2000 - 2016)

\begin{tabular}{|c|c|c|c|c|c|c|}
\hline المتوسط & النمو & $\mathbf{F}$ & $\mathbf{R}^{2}$ & المعـادلـة & المتغير & المعادلة \\
\hline 18014.1 & 9.05 & $41.5^{\circ *}$ & 0.734 & $\begin{array}{r}Y^{\wedge}=2705.8+1700.9 X_{t} \\
(6.44)^{* \prime \prime}\end{array}$ & قيمة الصادرات الكلية & 1 \\
\hline 40511.5 & 11.4 & $107.0^{* *}$ & 0.877 & $\begin{array}{r}Y^{\wedge}=1074.5+4620.7 X_{t} \\
(10.34)^{\prime \prime}\end{array}$ & قيمة الواردات الكلية & 2 \\
\hline 22497.4 & 13.0 & $74.4^{* *}$ & 0.832 & $\begin{array}{r}Y^{\wedge}=3780.3+2919.7 X_{t} \\
(8.63)^{* *}\end{array}$ & قيمة الميزان التجارى & 3 \\
\hline 1871.4 & 10.0 & $62.6^{* *}$ & 0.807 & $\begin{array}{r}Y^{\wedge}=179.5+188.0 X_{t} \\
(7.91)^{*}\end{array}$ & قيمة الصادرات الزراعية & 4 \\
\hline 3932.0 & 7.0 & $11.0^{* *}$ & 0.423 & $\begin{array}{r}Y^{\wedge}=1442.1+276.7 X_{t} \\
(3.32)^{* *}\end{array}$ & قيمة الواردات الزراعية & 5 \\
\hline 2060.6 & 7.0 & $4.9^{* *}$ & 0.245 & $\begin{array}{r}Y^{\wedge}=858.3+144.1 X_{t} \\
(2.20)^{\circ}\end{array}$ & قيمة الميزان الزراعى & 6 \\
\hline 125.6 & 11.5 & $55.1^{* *}$ & 0.786 & $\begin{array}{r}Y^{\wedge}=4.3+14.4 X_{t} \\
(7.42)^{\circ}\end{array}$ & قيمة صادرات البصل & 7 \\
\hline 377.4 & 7.7 & $8.8^{* *}$ & 0.371 & $\begin{array}{r}Y^{\wedge}=114.7+29.2 X_{t} \\
(2.97)^{* *}\end{array}$ & كمية صادرات البصل & 8 \\
\hline
\end{tabular}

المصدر : جمعت وحسبت من بيانات ملحق (1).

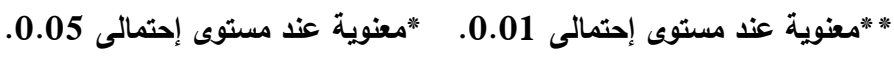

إحصائياً بلغ حوالى 144.1 مليون دولار يعادل حوالى مثلى 14.1 \% 7 من متوسطه السنوى خلال فترة الدراسة.

3- الوضع الراهن لتطور مؤشرات التجارة

الخارجية لمحصول البصل:

يتضح من دراسة الجدول رقم (1) أن قيمة صادرات

البصل قد تراوحت بين حد أدنى بلغ حوالى دالى 24.75 مليون دولار عام 2001 وحد أقصى بلغ حوالى دئ دئ
أما بالنسبة للميزان الزراعي الإجمالى فيتضح من دراسة بيانات ملحق (1) وجود عجز دائم فى الميزان

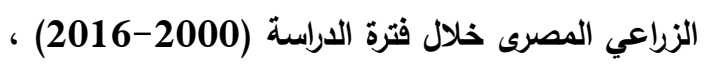
وقد قدر حده الأدنى بنحو 600.8 مليون دولار عام 2004 وحده الأقصى بنحو 6121.9 مليون دولار عام بلام 2012 بمتوسط سنوى بلغ حوالى 2064 وحلى مليون دولار ، كما يتضح من المعادلة رقم (6) أن العجز فئ فئوس

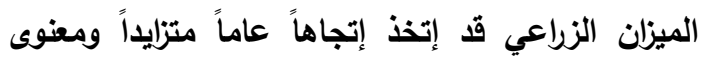


حيث يتضح من بيانات جدول (2) أن مؤثر النصيب

السوقي لصادرات البصل المصري قد تراوح بين حد أدنى بانى بلغ حوالى 2.75 \% عام 2006 وحد أعلى بلغ حوالى له 9.00\% عام 2009 بمتوسط بلغ حوالى 5.01 \% عام وحلى خلال الفترة (2000-2016) •

ويتقدير معادلة الإتجاه الزمني لتطور مؤثثر النصيب السوقى للصادرات المصرية من البصل خلال الفترة (2016-2000) تبين أنه اتخذ اتجاهاً عاماً متزايداً

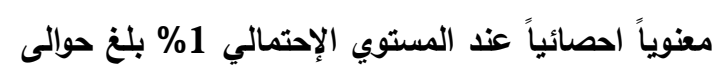
0.269 ، بمثل حوالى 5.37\% من المتوسط السنوي

البالغ حوالى 5.013 \% - معادلة (9)، جدول (1).

$Y^{\wedge}=2.922+0.269 X_{t}$

$$
\begin{array}{ll} 
& (3.84)^{\circ *} \\
F=14.7^{* *} \quad R^{2}=0.495
\end{array}
$$

Market مؤشر معدل إخترلق الأسواق Penetration Indictor المصرى فى أهم الأسواق الخارجية خلال متوسط الفترة (2008-2016) يقيس هذا المؤشر قدرة سلعة معينة على اخترلق أسواق تصديرية معينة، ويقاس هذا المؤثر بالصيغة الاتية:

$$
M P R_{i j}=\left[M_{i j t} /\left(Q_{i j}+M_{i j}-X_{i j}\right)\right]
$$

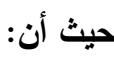

من البصل j من دولة معينة . تمثل واردات الدولة : Mijt

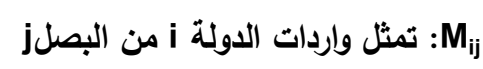
i تمثل انتاج البصل في الدول i تمثل صادرات البصل بواسطة الدولة :

وكلما ارتفعت قيمة مؤثر اخترلق السوق كلما دل

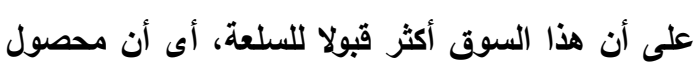

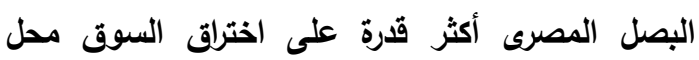

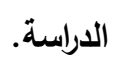

263.46 مليون دولار عام 2015 وقدر المتوسط السنوى قيمة صادرات البصل حوالى 125.62 مليون دولار خلال فترة الدراسة (2000-2016) ، هذادات البمل حولى وتثير المعادلة رقم (7) بجدول (1) إلى أن قيمة صادرات البصل قد إتخذت إتجاهاً عاماً متزايداً ومعنوى إحصائياً

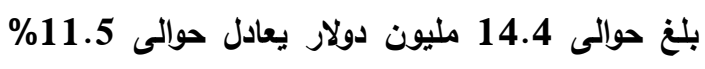
من متوسطها السنوى البالغ حوالى 14.4 مليون دلائ بعادل حلى 125.62 مليون دولار. أما بالنسبة كمية صادرات البصل فقد تراوحت بين حد أدنى بلغ حوالى 157.58 ألف طن عام 2000 وحد 219.1 ألف أقصى بلغ حوالى 1219.1 ألف طن عام 2015 وقلى طن عام المتوسط السنوى كمية صادرات البصل حوالى 377.43 ألف طن خلال فترة الدراسة (2000-2016) ، ويتضو

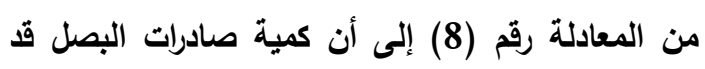
إتخذت إتجاهاً عاماً متزليداً ومعنوى إحصائياً بلغ حوالى انى

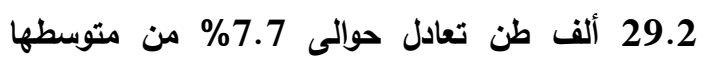

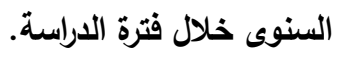

ثانياً: مؤثرات القدرة التنافسية للصادرات المصرية من البصل فى أهم الأسواق الخارجية: يتناول هذا الجزء قياس القدرة التنافسية للصادرات الفيوات الفاريه المصرية من البصل فى أهم الأسواق الخارجية من خلال

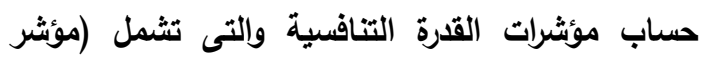

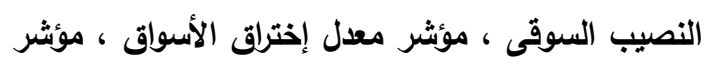

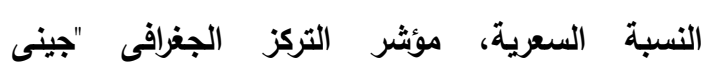
هيرشمان"، مؤشر الميزة النسبية الظاهرية) .

1- مؤثر النصيب السوقى لصادرات البصل المصرى فى أهم الأسواق الخارجية خلال الفترة (2000-2016) ويتم حسابه، من خلال قسمة قيمة صادرات الدولة من سلعة معينة إلى إجمالي قيمة الصادرات العالمية من فن فئل

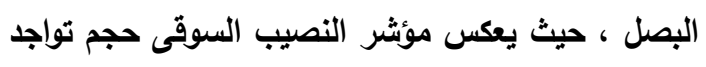
الاولة المصدرة فى الأسواق الخارجية. 
جدول (2): تطور مؤثر النصيب السوقى للصادرات المصرية من محصول البصل خلال الفترة (2000-2016)

\begin{tabular}{|c|c|}
\hline نسبة النصيب السوقى لمحصول البصل & 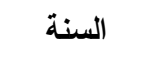 \\
\hline 3.45 & 2000 \\
\hline 2.84 & 2001 \\
\hline 4.06 & 2002 \\
\hline 3.93 & 2003 \\
\hline 4.29 & 2004 \\
\hline 4.01 & 2005 \\
\hline 2.75 & 2006 \\
\hline 3.36 & 2007 \\
\hline 6.10 & 2008 \\
\hline 9.00 & 2009 \\
\hline 7.63 & 2010 \\
\hline 7.45 & 2011 \\
\hline 6.38 & 2012 \\
\hline 6.18 & 2013 \\
\hline 5.48 & 2014 \\
\hline 7.94 & 2015 \\
\hline 5.97 & 2016 \\
\hline 5.013 & المتوسط \\
\hline 0.269 & مقدار التغير \\
\hline 5.37 & معدل النمو \\
\hline $14.7^{* *}$ & $\mathbf{F}$ \\
\hline 0.495 & $\mathbf{R}^{2}$ \\
\hline
\end{tabular}

المصدر : جمعت وحسبت من بيانات ملحق (1)،(2).

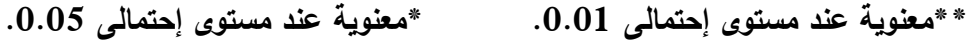

الأسواق بنحو 57.8\% ، 34.9\% ، 25.4 ، 15.9\% ، 15.5\% على التوالى ، بينما كانت أسواق إيطاليا رومانيا ، المملكة المتحدة هى أسواق لم يستطع ل15.

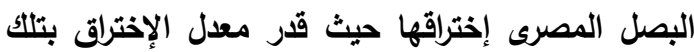
الأسواق بنحو 1.4\% ، 1.5\% ، 2.1\% على التوالى.
ويتضح من دراسة الجدول رقم (3) أن محصول البصل أكثر قدره على إختراق أسواق الدول العربية مقارنة بالأسواق الأجنبية وأن السوق السعودى هو أكبر الأسواق التى يخترقها البصل المصرى يلى ذلك أسواق الكويت ،

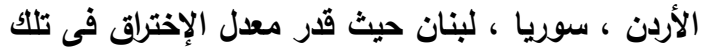


جدول (3): متوسط معدل اختراق الأسواق لصادرات البصل المصرى في أهم الأسواق الدولية خلال الفترة (2008(الكمية : ألف طن) (2016)

\begin{tabular}{|c|c|c|c|c|c|}
\hline معدل إختراق & كميةصادرات & كمية إنتاج & كمية وارادات & كمية صادرات مصر من & الدولة \\
\hline 57.8 & 29.1 & 86.5 & 257.6 & 182.076 & السعودية \\
\hline 34.9 & 0.2 & 13.8 & 55.6 & 24.085 & الكويت \\
\hline 25.4 & 1.8 & 27.4 & 32.2 & 14.659 & الاردن \\
\hline 15.9 & 19.6 & 89.3 & 24.1 & 14.907 & سوريا \\
\hline 15.5 & 17.5 & 70.4 & 14.9 & 10.49 & لبنان \\
\hline 7.0 & 0.2 & 7.4 & 49.1 & 3.919 & عمـان \\
\hline 6.8 & 1127 & 1268.5 & 146.2 & 19.528 & هولندا \\
\hline 6.3 & 16.7 & 0 & 203.7 & 11.725 & الامارات \\
\hline 5.6 & 7 & 1793.3 & 424 & 124.1 & روسيا الأتحاديه \\
\hline 5 & 0.1 & 183.6 & 9.69 & 9.609 & ليبيا \\
\hline 3.4 & 0 & 94.4 & 72.9 & 5.608 & العراق \\
\hline 2.1 & 7.9 & 351.3 & 362.6 & 14.516 & المملكة المتحدة \\
\hline 1.5 & 1.4 & 375.2 & 38.3 & 6.177 & رومانيا \\
\hline 1.4 & 40.2 & 382.1 & 65.8 & 5.782 & ايطاليا \\
\hline
\end{tabular}

المصدر : جمعت وحسبت من : الموقع الإكترونى لمنظمة الأغنية والزراعة العالمية: لهww.fao.org

بالأسواق الدولية، حيث بلغ حوالى 2.570 ، 2.295 ، 1.701 .103 ، 1.030 ، 1.017 ، 1.03

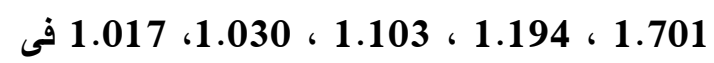

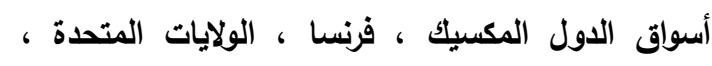

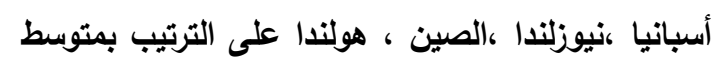

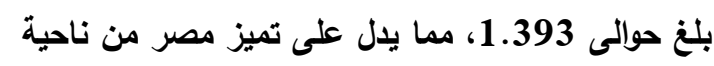

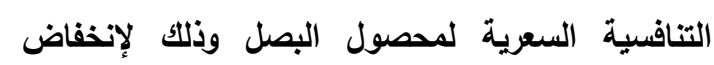
أسعاره التصديرية بالمقارنة بأسواق الدول الأخرى.
3- مؤشر النسبة السعرية لسعر تصدير البصل

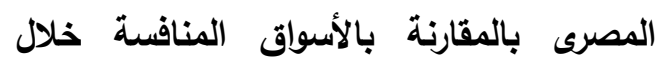
متوسط الفترة (2000-2016) بالمفانه بالاسون ويتم حسابه، من خلال قسمة سعر تصدير مصر

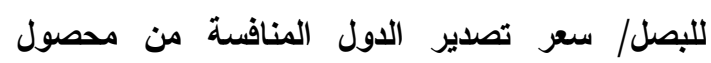
البصل. حيث يتضح من البيانات الواردة بجدول (4) إرتفاع مؤشر النسبة السعرية للبصل المصري بالمقارنة 
جدول (4): مؤثر النسبة السعرية بين أهم الدول المنافسة لمحصول البصل المصري خلال متوسط الفترة (2000(2016

\begin{tabular}{|c|c|}
\hline مؤثشر النسبة السعرية & الاولة \\
\hline 2.570 & المكسيك \\
\hline 2.295 & فرنسا \\
\hline 1.701 & الولايات المتحدة \\
\hline 1.194 & أسبانيا \\
\hline 1.103 & نيوزلتدا \\
\hline 1.030 & الصين \\
\hline 1.017 & هولندا \\
\hline 0.898 & بيرو بي \\
\hline 0.732 & الهند \\
\hline 1.393 & المتوسط \\
\hline
\end{tabular}

www.trademap.org المصدر : جمعت وحسبت من : الموقع الإكترونى لخريطة التجارة الخارجية

: $X_{i}$ البصل.

وتقع قيمة مؤثثر التركز الجغرافى بين الصفر والواحد

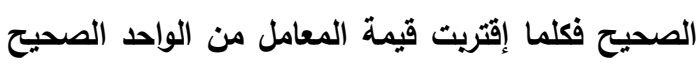

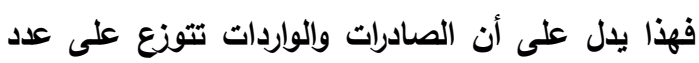

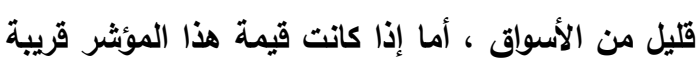
من الصفر دل ذلك على التوسع فى الأسواق .

هذا ويتضح من مؤثرات الجدول رقم (5) أن قيمة معامل التركز الجغرافى لكل من كمية وقيمة الصادرات المصرية من البصل قـ إقتربت من الصفر جيث بلغت الجن حوالى 0.48 وهو مايعكس تعدد الأسواق المستقبلة للصادرات المصرية من البصل وإتساعها.
4- مؤشر التركز الجغرافى جينى هيرشمان Gini لصادرات البصل المصرى خلال متوسط الفترة (2008- 2016) ويعبر مؤثر تركز الصادرات عن درجة اعتماد

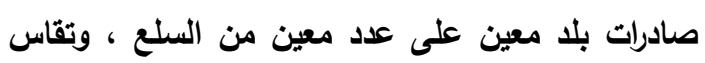

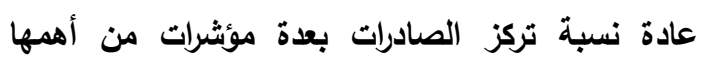

$$
\text { مؤثر جينى هيرشمان: } C_{j x}=100 \sqrt{\Sigma\left(\frac{X_{s j}}{X_{i}}\right)^{2}}
$$

حيث أن: C : تمثل معامل التركز الجغرافي لكمية وقيمة الصادرات المصرية من البصل. : X $X_{s j}$ والموجهة إلى دولة معينة. 
حيث توجد عده أسواق دولية لإستيراد البصل إليها حوالى 182.076 ألف طن يمثل حوالى 38.07 من متوسط إجمالي كمية الصادرات المصرية

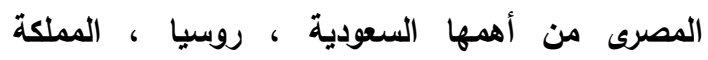

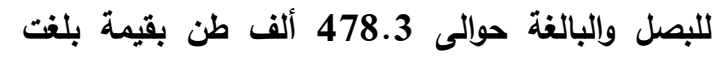

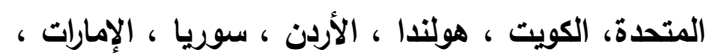

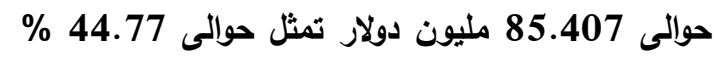
ليبيا ، لبنان ، إيطاليا ، رومانيا ، العرلق ، عمان. من متوسط إجمالي قيمة الصادرات المصرية للبصل دارل والبالغ حوالى 190.78 مليون دولار خلال متوسط الفترة

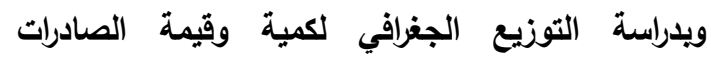
المصرية للبصل خلال متوسط الفترة (2008- 2016) . (2016-2008) يتضح أن السعودية احتلت المرتبة الأولى في استيراد

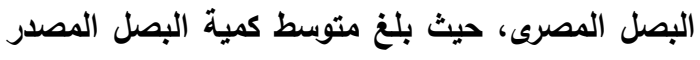

جدول (5): التوزيع الجغرافى للبصل المصرى خلال متوسط الفترة (2008-2016) (الكمية:ألف طن-القيمة:مليون دولار)

\begin{tabular}{|c|c|c|c|c|c|c|}
\hline الجغرافى للقيمة & $\%$ & قصر من البصل صادرات & الجغرافى للكمية التركز & $\%$ & كصر من البصل صادرات & الاولة \\
\hline 0.200 & 44.77 & 85.407 & 0.145 & 38.07 & 182.076 & السعودية \\
\hline 0.013 & 11.26 & 21.473 & 0.067 & 25.95 & 124.1 & روسيا الأتحاديه \\
\hline 0.005 & 7.17 & 13.68 & 0.001 & 3.03 & 14.516 & المملكة المتحدة \\
\hline 0.003 & 5.34 & 10.187 & 0.003 & 5.04 & 24.085 & الكويت \\
\hline 0.003 & 5.11 & 9.751 & 0.002 & 4.08 & 19.528 & هولندا \\
\hline 0.001 & 3.48 & 6.637 & 0.001 & 3.06 & 14.659 & الاردن \\
\hline 0.001 & 3.02 & 5.757 & 0.001 & 3.12 & 14.907 & سوريا \\
\hline 0.001 & 2.94 & 5.608 & 0.001 & 2.45 & 11.725 & الامارات \\
\hline 0.001 & 2.40 & 4.576 & 0.000 & 2.01 & 9.609 & ليبيا \\
\hline 0.000 & 2.21 & 4.22 & 0.000 & 2.19 & 10.49 & لبنان \\
\hline 0.000 & 1.61 & 3.062 & 0.000 & 1.21 & 5.782 & ايطاليا \\
\hline 0.000 & 1.23 & 2.347 & 0.000 & 1.29 & 6.177 & رومانيا \\
\hline 0.000 & 1.20 & 2.29 & 0.000 & 1.17 & 5.608 & العرلق \\
\hline 0.000 & 0.99 & 1.896 & 0.000 & 0.82 & 3.919 & عمـان \\
\hline 0.005 & 7.28 & 13.887 & 0.004 & 6.51 & 31.12 & دول أخرى \\
\hline 0.48 & 100 & 190.78 & 0.47 & 100 & 478.3 & الإجمالى \\
\hline
\end{tabular}

المصدر : جمعت وحسبت من : الموقع الإكترونى للجهاز المركزى للتعبئة العامة والإحصاء:بw.capmas.gov.eg 


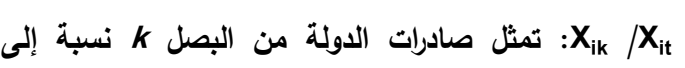

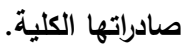

: تمثل صادرات العالم من البصل K إلى اجمالي

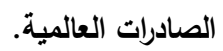

وعندما يأخذ هذا المؤشر قيمة أكبر من الواحد الصحيح فإن ذلك يدل على تمتع هذه الصناعة بميزة

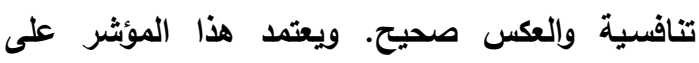
بيانات الصادرات فقط، وذلك لان الصادرات تعطي اختبارا

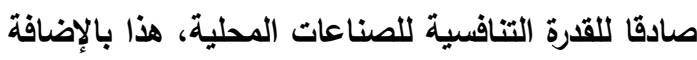
إلى أن نمو الصادرات للاول النامية له علاقة وثيقة بالتحسن في مستوى المعيشة. حيث يتضح من بيانات جدول (6) أن مؤثر الميزة النسبية الظاهرية لصادرات البصل المصري من إجمالى

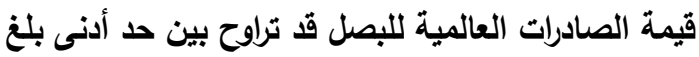
حوالى 22.22\% عام 2001 وحد أعلى بلغ حوالى

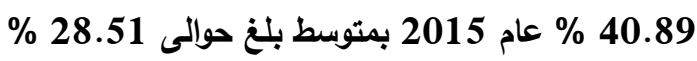

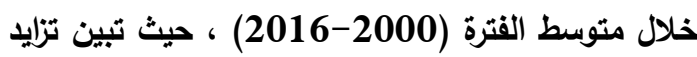
مؤثر الميزة النسبية الظاهرية لصادرات البصل المصري من حوالى 27.88 \% عام 2000 ع 2016 إلى حوالى

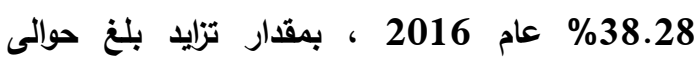
19.36 \% من عام 2000. كما يتضح أن قيمة مؤثر الميزة النسبية الظاهرية لصادرات البصل المصرى قد زادت عن الواحد الصحيح مما يغني أن مصر تتمتع بميزة نسبية ظاهرية في تصدير البصل خلال الفترة (2000. 2016

ويتقدير معادلة الإتجاه الزمني لتطور مؤثر الميزة النسبية الظاهرية لمحصول البصل خلال متوسط الفترة (2016-2000) تبين أنه اتذذ اتجاهاً عاماً متزايداً

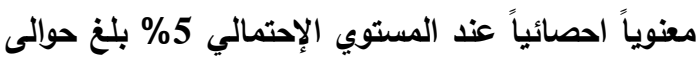
\%.599، يمثل حوالى 2.1\% من المتوسط السنوي البالغ حوالى 28.51\% - جدول حولى (6).
فى حين احتلت روسيا المرتبة الثانية في قيمة

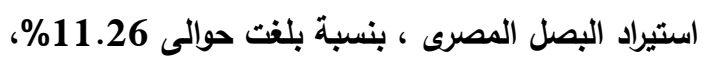

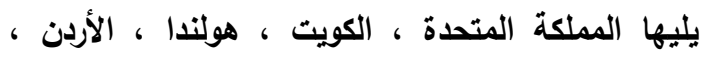

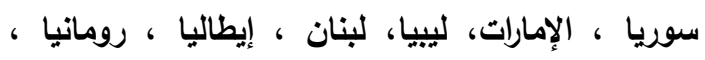

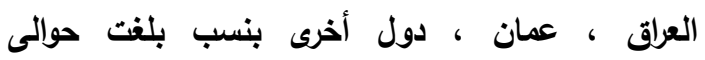
،3.02 \% \% 3.48 ، \% 5.11 \% \% 3.34 ، 7.17 ،\% 1.23 ،\% 1.61 ، \%2.21 ،\% 2.4 ،\% 2.94 1.2 \% ، 0.99\%، 7.28 \% على الترتيب من إجمالى قيمة الصادرات المصرية للبصل خلال متوسط الفترة .2016-2008) كما تبين أن معامل التركز الجغرافي لكمية صادرات البصل قد بلغ حوالي 0.47 ، فى حين بلغ معامل التركز الجغرافي لقيمة صادرات البصل حوالي 0.48 خلال متوسط الفترة (2008- 2016)، ويعتبر معامل التركز الجغرافي مرتفع نسبياً، حيث زاد عن 0.4 ـ كما يتبين وجود تباين فى متوسط سعر تصدير البصل المصرى بين ندين مختلف الدول المستوردة، حيث تراوح متوسط سبعر التصدير بين حد أدنى بلغ حوالى 173.03 دولار/ طن لروسيا وحد أعلى بلغ حوالى 942.4 دولار/ طن دائل

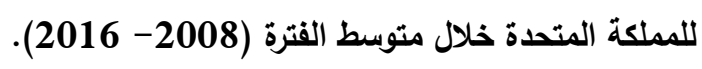

5- مؤشر الميزة النسبية الظاهرية Comparative Revealed Advantage Indictor البصل المصرى فى أهم الأسواق الخارجية خلال متوسط الفترة (2000-2016):

ويعكس مؤثر الميزة النسبية الظاهرة الكفاءة الاقتصادية للموارد الحقيقية، حيث يقيس صادرات دولة ما من سلعة معينة في هيكل صادرات هذه الدولة

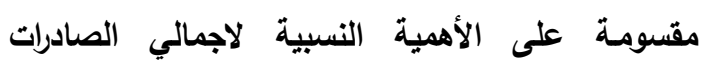
العالمية ويأخذ هذا المؤثر الصيغة الاتية: R.C.A $=\left(X_{i k} / X_{i t}\right) /\left(X_{w k} / X_{w t}\right)$ 
جدول (6): تطور مؤشر الميزة النسبية الظاهرية لمحصول البصل خلال الفترة (2000-2016)

\begin{tabular}{|c|c|}
\hline مؤثر الميزة النسبية الظاهرية & السنة - ال \\
\hline 27.88 & 2000 \\
\hline 22.22 & 2001 \\
\hline 26.80 & 2002 \\
\hline 26.60 & 2003 \\
\hline 23.60 & 2004 \\
\hline 28.52 & 2005 \\
\hline 23.22 & 2006 \\
\hline 24.44 & 2007 \\
\hline 31.17 & 2008 \\
\hline 28.85 & 2009 \\
\hline 26.42 & 2010 \\
\hline 32.50 & 2011 \\
\hline 31.81 & 2012 \\
\hline 30.09 & 2013 \\
\hline 26.41 & 2014 \\
\hline 40.89 & 2015 \\
\hline 33.28 & 2016 \\
\hline 28.51 & المتوسط \\
\hline 0.599 & مقدار التغير \\
\hline 2.10 & معدل النمو \\
\hline $11.6^{* *}$ & $\mathbf{F}$ \\
\hline 0.436 & $\mathbf{R}^{2}$ \\
\hline
\end{tabular}

المصدر : جمعت وحسبت من بيانات ملحق (1)،(2).

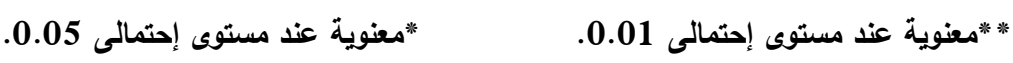

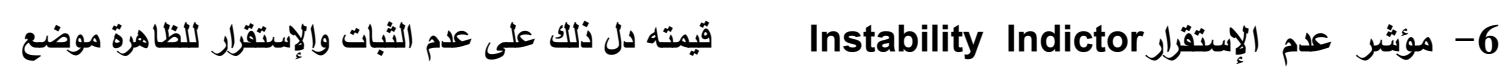

لكمية صادرات البصل المصرى خلال متوسط الداسة .

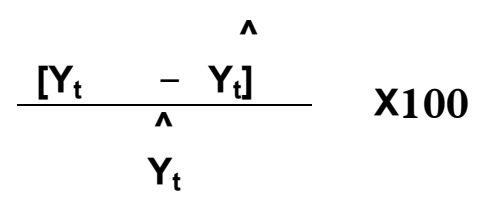

حيث Yt تثير إلى كمية أو قيمة الصادرات المصرية من البصل.

$$
\text { (الفترة (2000-2016) }
$$

يعبر معامل عدم الإستقرار عن الميزة النسبية والتنافسية

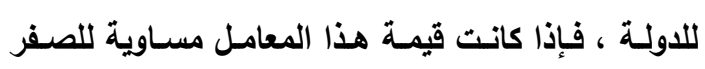

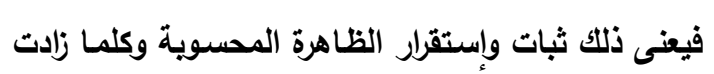


عدم الإستقرار لكمية صادرات البصل قد بلغ إتجاه عام

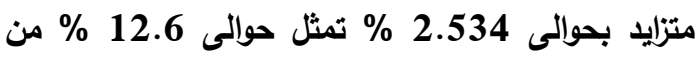
المتوسط البالغ حوالى 20.11\% خلى 2016 بلال متوسط الفترة

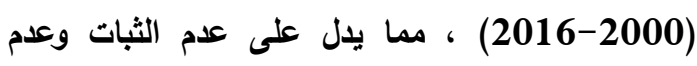
الإستقرار لكمية الصادرات المصرية من البصل خلال فترة الاراسة.
Y⿳㇒t

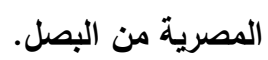
حيث يتضح من بيانات جدول (7) أن مؤثر عدم

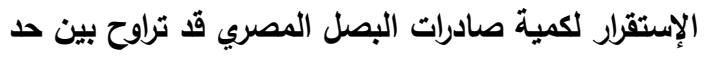

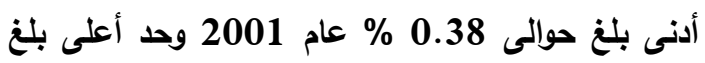
حوالى 109.54 \% عام 2015 ، حيث تبين أن مؤثر بل

جدول (7): تطور مؤشر عدم الإستقرار لكمية الصادرات المصرية من البصل خلال الفترة (2000-2016)

\begin{tabular}{|c|c|}
\hline مؤثر عدم الإستقرار لكمية الصادرات المصرية من & السنة \\
\hline 9.53 & 2000 \\
\hline 0.38 & 2001 \\
\hline 50.32 & 2002 \\
\hline 43.59 & 2003 \\
\hline 31.34 & 2004 \\
\hline 9.80 & 2005 \\
\hline 30.81 & 2006 \\
\hline 37.43 & 2007 \\
\hline 28.45 & 2008 \\
\hline 37.11 & 2009 \\
\hline 17.56 & 2010 \\
\hline 5.55 & 2011 \\
\hline 29.64 & 2012 \\
\hline 28.99 & 2013 \\
\hline 33.60 & 2014 \\
\hline 109.54 & 2015 \\
\hline 15.71 & 2016 \\
\hline 20.11 & المتوسط \\
\hline 2.534 & مقدار الزيادة \\
\hline 12.6 & معدل النمو \\
\hline $5.6 *$ & $F$ \\
\hline 0.27 & $\mathbf{R}^{2}$ \\
\hline
\end{tabular}

المصدر : جمعت وحسبت من بيانات ملحق (1)،(2). |مغنوية عند مستوى إحتمالى

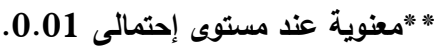


بتقدير دالة الطلب على البصل المصرى فى السوق

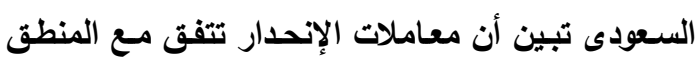

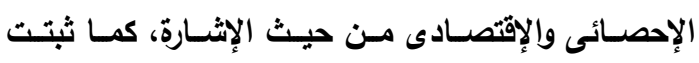
معنوية معاملات الإنحدار عند مستوى معنوية (0.01) ،

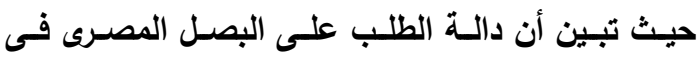

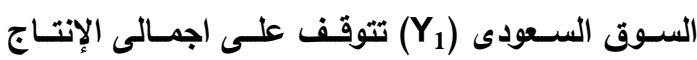
المحلى من البصل بالألف طن (X) ) ، اجمالى الإستهلاك

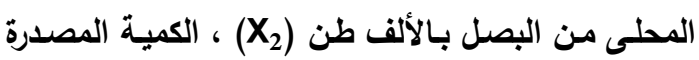

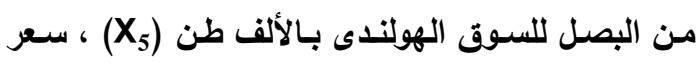

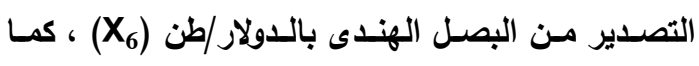

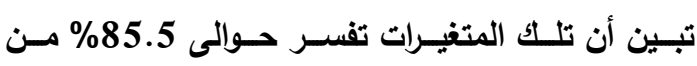

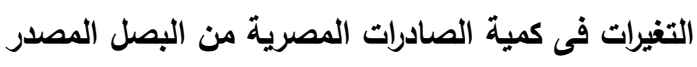

$$
\text { للسوق السعودى. }
$$

$Y_{1}=91.184+0.686 X_{1}-0.572 X_{2}-0.159 X_{5}-0.418 X_{6}$

$$
\mathrm{F}=12.8 \quad \mathrm{R}^{-2}=\mathbf{0 . 8 5 5} \quad \text { D. } W=1.8
$$

حيث تبين من النموذج الذطى وجود علاقة طردية بين كمية الصادرات المصرية من البصل للسوق السعودى (Y) وإجمالى الإنتاج المحلى من البصل بالألف طن (X)

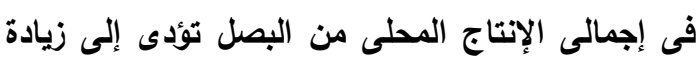

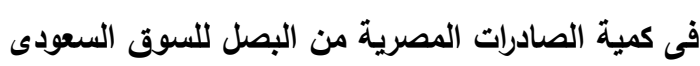
تقدر بحوالى 0.686 ألف طن.فى حين تبين وجود علاقة عكسية بين كمية الصادرات المصرية من البصل

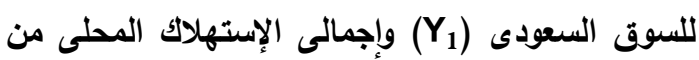

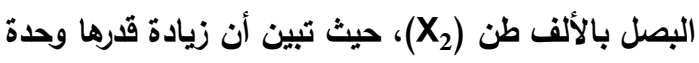

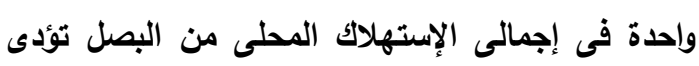

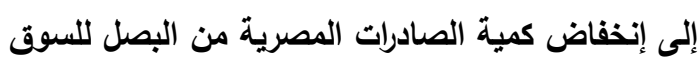
السعودى بحوالى 0.572 ألف طن. كما تبين وجود علاقة عكسية بين كمية الصادرات المصرية البصل للسوق السعودى (Y) وإجمالى الكمية

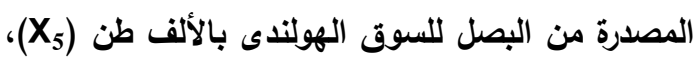

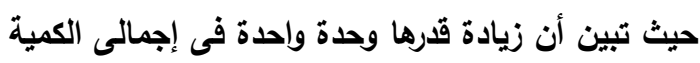

ثالثاً: التقدير القياسـى لـدوال الطلب علـى البصـل المصرى فـى أهـم الأسـواق الخارجيـة خـلال

$$
\text { القترة (2000-2016): }
$$

تم إجراء التقدير القياسى لدالة الطلب على البصل

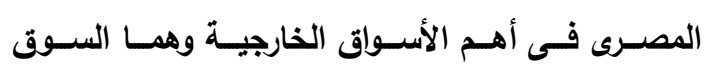
السـعودى والســوق الروســ خــلال القتــرة (2000-

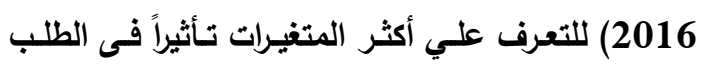
على البصل المصرى فى تلك الأسواق الخارجية ، وذلك التك

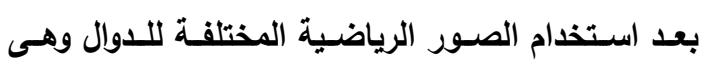

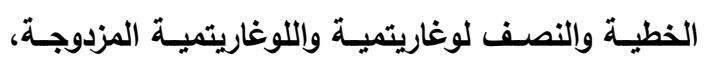
حيث تم إختيار أفضل هذه الصور إستناداً إلى قيم (t)

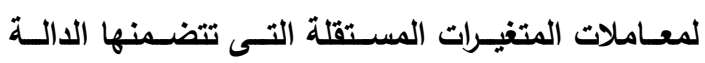

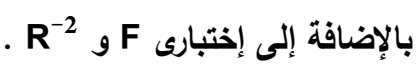

تنظوى متغيرات دوال الطلب الخارجى على البصل

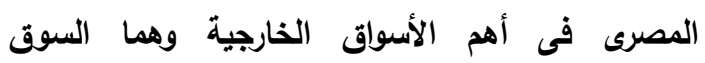

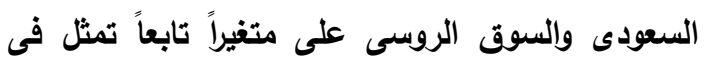

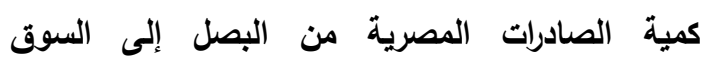
السعودى (Y1) بالألف طن أو كمية الصادرات المصرية من البصل إلى السوق الروسى (Y) بالألف طن وعدة

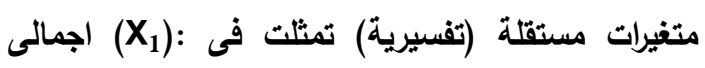
الإنتاج المحلى من البصل بالألف طن، (X2) اجنمات فئلى

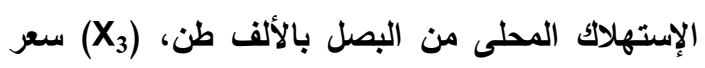

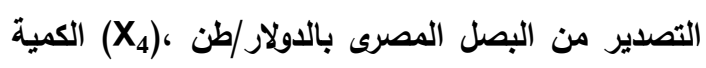

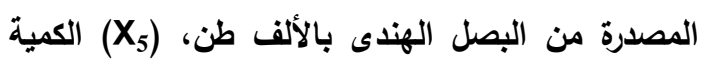

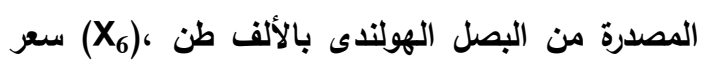

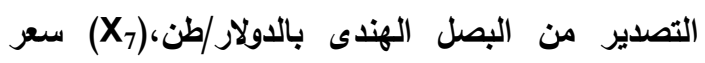

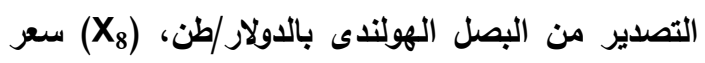
الصرف الرسمى بالجنية/دولار.

1 - التقــدير القياسـى لدالـة الطلب علـى البصـل المصــرى الســوق الســعودى خــلال الفتــرة

:(2016-2000) 
للسوق الروسى (Y2) وسعر تصدير البصل الهندى (X) بالدولار/طن (X)

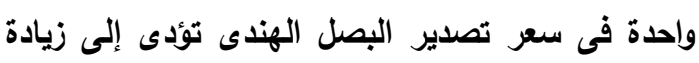

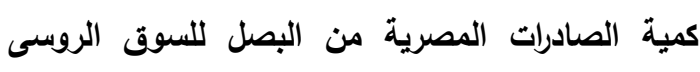

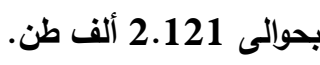

رابعاً: التنبؤ بصادرات البصل المصرى فى أهم الأسواق الخارجية حتى عام 2020 بإستخدام

Box- " منهجية بوكس مينكيز

\section{:"Jenkins}

يهرف هذا الجزء إلى التبؤ بكمية صادرات محصول

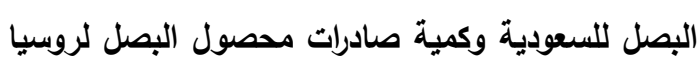

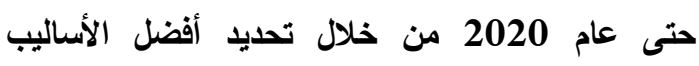
القياسية المستخدمة في التنبؤ بإستخدام نموذج (بوكس

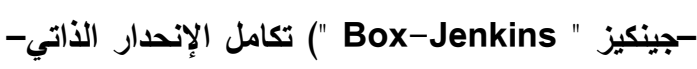
Autoregressive Integrated " الوسط المتحرك " (ARIMA) "Moving Average ) ، حتى يمكن التعرف

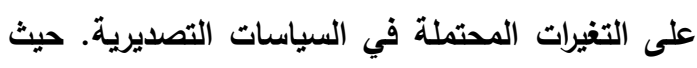

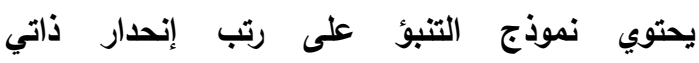
Autoregressive متحرك Moving Average لحد الخطأ من الارجة

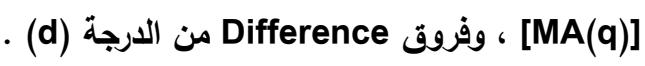

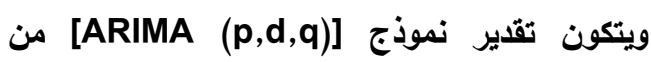
أربعة مراحل يمكن توضيحها كالتالي :

$$
\text { 1-مرحلة التعريف: }
$$

1- بـإجراء الرســم البيـاني للبيانسات الأصـلية لكميـة

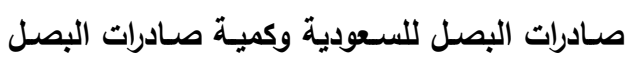

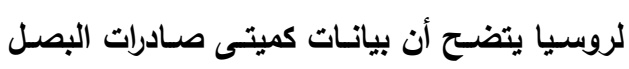

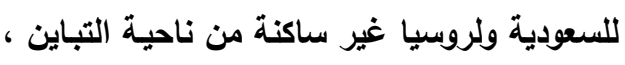

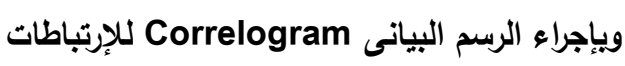

الرجعية الذاتية AC ، والذاتيـة الجزئية البية كمية صـادرات البصل للسعودية (ثكل 1) وكمية التية صادرات البصل لروسيا (شكل 2)، تبين أن معامل
المصدرة من البصل للسوق الهولندى تؤدى إلى إنخفاض الهـاد

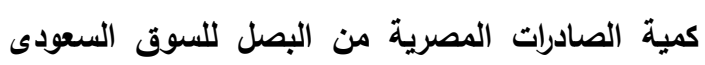
بحوالى 0.159 ألف طن.فى حين تبين وجود علاقة

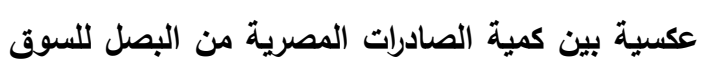

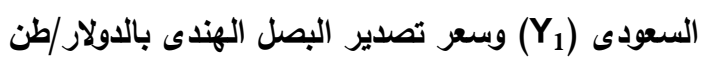
(X) تصدير البصل الهندى تؤدى إلى إنخفاض كمية الصادرات المصرية من البصل للسوق السعودى بحوالى 0.418 ألف طن. 2 - التقــير القياسـى لدالـة الطلب على البصـل

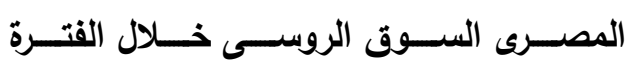
:2016-2000) ويتقدير دالة الطلب على البصل المصرى فى السوق

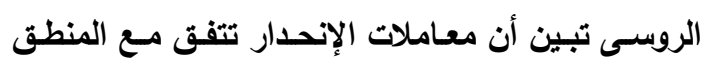

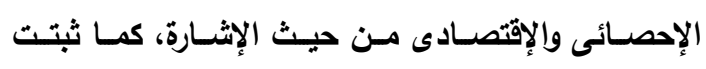

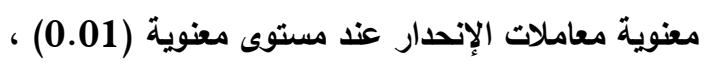

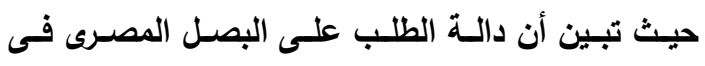

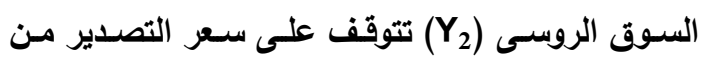

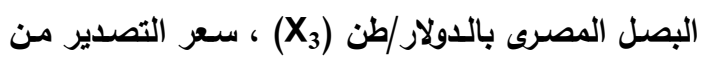

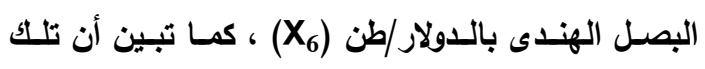

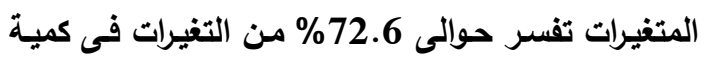
الصادرات المصرية من البصل المصدر للسوق الروسى.

$$
\begin{array}{ccc}
Y_{2}=120.26 & -0.631 X_{3}+2.121 X_{6} \\
& (-2.43)^{*}(3.32)^{* *} \\
F=6.3 \quad R^{-2}=0.726 \quad \text { D.W }=2.0
\end{array}
$$

حيث تبين من النموذج الخطى وجود علاقة عكسية بين كمية الصادرات المصرية من البصل للسوق الروسى النودئ وسعر التصدير من البصل المصرى بالدولار/طن

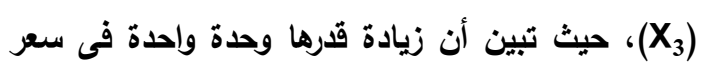

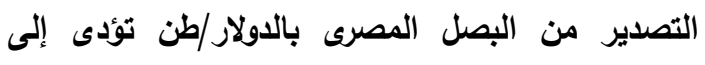

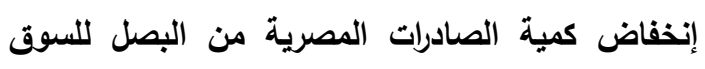
الروسى بحوالى 0.631 ألف طن.فى حين تبين وجود الغفارد علاقة طردية بين كمية الصادرات المصرية من البصل 


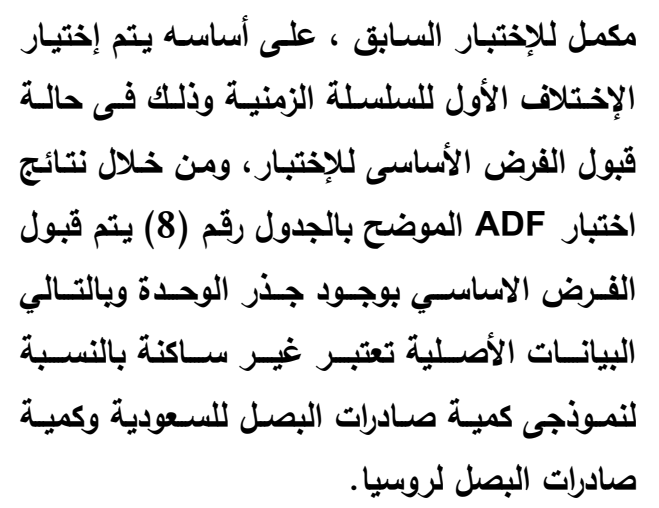

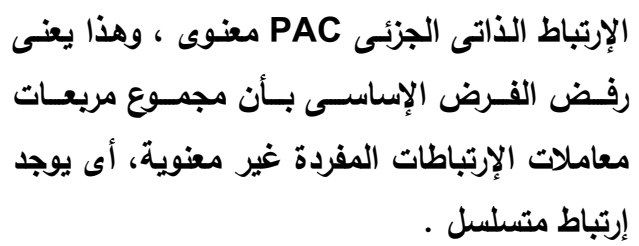

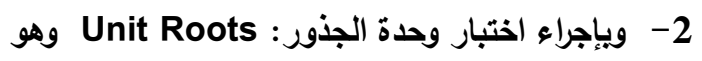

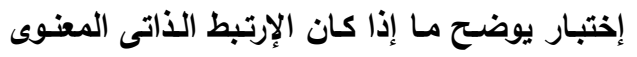

السابق إكتثافه فى Correlogram يكافئ الواحد

أم لا، حيث 1 Ho : $\rho_{1}=1$ ويعتبر هذا الإختبار

\section{Correlogram of $\mathrm{D}(\mathrm{Y} 1)$}

Date: $05 / 02 / 17$ Time: $22: 37$

Sample: 20002016

Included observations: 16

\begin{tabular}{|c|c|c|c|c|c|c|c|c|}
\hline \multicolumn{2}{|c|}{ Autocorrelation } & \multicolumn{2}{|c|}{ Partial Correlation } & & $A C$ & PAC & Q-Stat & Prob \\
\hline 나 & I & 나 & 1 & & -0.087 & -0.087 & 0.1443 & 0.704 \\
\hline $1 \quad 4$ & 1 & & 1 & & -0.127 & -0.136 & 0.4769 & 0.788 \\
\hline $1 \square$ & 1 & $1 \square$ & 1 & & -0.254 & -0.285 & 1.9016 & 0.593 \\
\hline 1 - & 1 & $1 \square$ & 1 & & -0.166 & -0.275 & 2.5630 & 0.633 \\
\hline 1 & 1 & $1 \square$ & 1 & & -0.025 & -0.216 & 2.5790 & 0.765 \\
\hline 1 & 1 & 1 & 1 & 6 & 0.256 & 0.063 & 4.4674 & 0.614 \\
\hline 1 & 1 & 1 & 1 & 7 & 0.107 & 0.017 & 4.8319 & 0.680 \\
\hline 1 & 1 & । & 1 & 8 & 0.007 & 0.005 & 4.8339 & 0.775 \\
\hline $1 \square$ & 1 & 14 & 1 & & -0.251 & -0.197 & 7.4286 & 0.593 \\
\hline 1 & 1 & 17 & 1 & 10 & 0.060 & 0.105 & 7.6001 & 0.668 \\
\hline 1 & I & 1 & 1 & 11 & -0.088 & -0.076 & 8.0504 & 0.709 \\
\hline 14 & 1 & $1 \square$ & 1 & 12 & -0.084 & -0.270 & 8.5542 & 0.740 \\
\hline
\end{tabular}

الثكل رقم (1) إختبار الإرتباطات الرجعية الذاتية والذاتية الجزئية لكمية صادرات البصل للسعودية

\section{Correlogram of $\mathrm{D}(\mathrm{Y} 2)$}

Date: $05 / 02 / 17$ Time: $23: 43$

Sample: 20002020

Included observations: 16

\begin{tabular}{|c|c|c|c|c|c|c|c|c|}
\hline \multicolumn{2}{|c|}{ Autocorrelation } & \multicolumn{2}{|c|}{ Partial Correlation } & \multicolumn{2}{|r|}{$\mathrm{AC}$} & PAC & Q-Stat & Prob \\
\hline $1 \square$ & 1 & $1 \square$ & I & 1 & -0.351 & -0.351 & 2.3709 & 0.124 \\
\hline $1 \square$ & 1 & $1 \square$ & 1 & 2 & -0.211 & -0.382 & 3.2871 & 0.193 \\
\hline 1 & 1 & $1 \square$ & 1 & 3 & 0.069 & -0.224 & 3.3912 & 0.335 \\
\hline 1 & 1 & 1 & 1 & 4 & 0.304 & 0.226 & 5.6041 & 0.231 \\
\hline $1 \square$ & 1 & $1 \square$ & 1 & & -0.374 & -0.193 & 9.2590 & 0.099 \\
\hline 1 & 1 & 1 - & 1 & 6 & -0.003 & -0.139 & 9.2594 & 0.160 \\
\hline 1 & 1 & $1 \square$ & 1 & 7 & 0.023 & -0.269 & 9.2756 & 0.233 \\
\hline 1 & 1 & 1 & 1 & 8 & 0.183 & -0.008 & 10.476 & 0.233 \\
\hline 1 다 & 1 & I & 1 & 9 & -0.162 & 0.038 & 11.559 & 0.239 \\
\hline 17 & 1 & 1 & 1 & 10 & 0.069 & 0.076 & 11.785 & 0.300 \\
\hline 1 & 1 & 1 & 1 & 11 & -0.015 & -0.023 & 11.799 & 0.379 \\
\hline 1 & 1 & 1 口 & 1 & 12 & 0.022 & -0.144 & 11.834 & 0.459 \\
\hline
\end{tabular}

الثكل رقم (2) إختبار الإرتباطات الرجعية الذاتية والذاتية الجزئية لكمية صادرات البصل لروسيا 
جدول رقم (8): نتائج إختبار Augmented Dickey Fuller (ADF)

\begin{tabular}{|c|c|c|c|}
\hline$D(2)$ & $D(1)$ & Level & Variable \\
\hline-6.081 & -3.932 & -1.657 & $\left(Y_{1}\right)$ كمية صادرات البصل المصدرة للسعودية صادرات البصل المصدرة لروسيا 1 (Y) \\
\hline-2.743 & -3.975 & $3.814-$ & Test critical values:5\% \\
\hline
\end{tabular}

المصدر: جمت وحسبت من: بيانات ملحق (1) بالدراسة بإستخذام برنامج 6 (1) E-views الفرق الأول D(1) D(2)

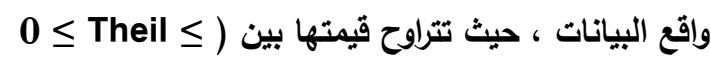

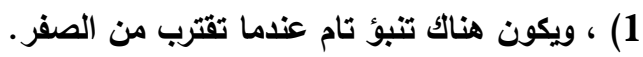
4-

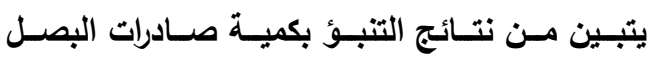

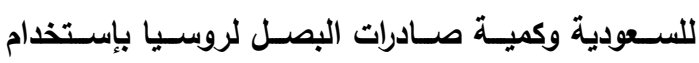

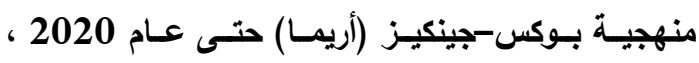

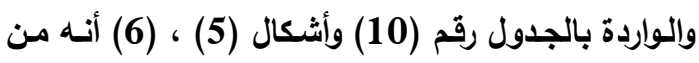

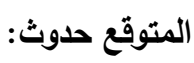
1. زيادة كمية صـادرات محصول البصل للسعودية من حوالى 258.2 ألـف طن عـام 2016 إلى حسالي 325.18 ألف طن عام 2020 بزيادة قدرث بحوالى 6725 ألى 67 ألف طن تمثل حوالى 25.95 \% مقارنـة بعام

.2016

2. زيسادة كميـة صـادرات محصسول البصل لروسيا مـن حوالى 35.89 ألـف طن عـام 2016 إلسى حوالي 50.14 ألف طن عام 2020 بزيـادة قدرث بحوالى 14.26 ألنف طن تمثل حوالى 39.73 \% عام 39.14 مقارنـة

$$
\text { بعام } 2016 .
$$

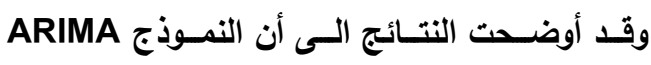

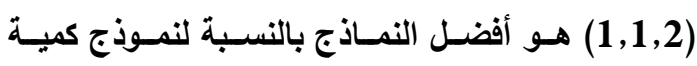

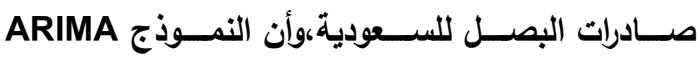

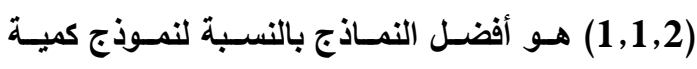

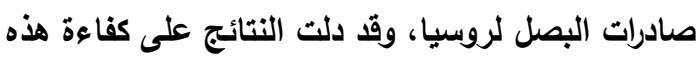

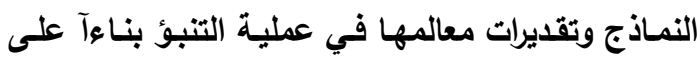
تحليل البواقي (الخطأ) وقد كانت النتائج أقرب ما تكون

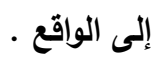

2-مرحلة تقدير النماذج: $\mathrm{D}\left(\operatorname{LOG}\left(\mathrm{Y}_{1}\right)\right)=0.0612+[\mathrm{AR}(1)=-0.5535, \mathrm{MA}$

$$
\text { (2) }=-0.9607]
$$

ARIMA $(1,1,2)$ ويسمى نموذج $\mathrm{D}\left(\operatorname{LOG}\left(\mathrm{Y}_{2}\right)\right)=0.0538+[\mathrm{AR}(1)=-0.7317, \mathrm{MA}$

(2) $=-0.9534]$

ARIMA $(1,1,2)$ ويسمى نموذج

3- مرحلة فحص قرة النماذج التنبوئة:

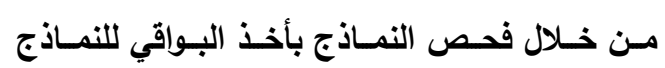

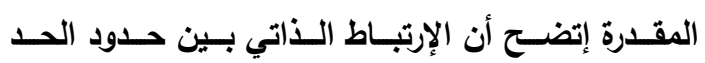
العشـوائي غير مغنـوي ويالتـالي تكون النمـاذج ملائمسة

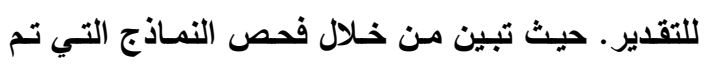
تقديرها حتى عـام 2020 ، أن النمـوذج ، فى حين تبين النموذج $(1,1,2)$ ARIMA

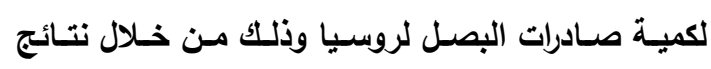
الاختبارات الموضحة بالجدول رقم (9) وكذلك من خلال

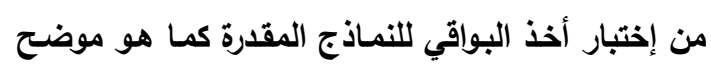

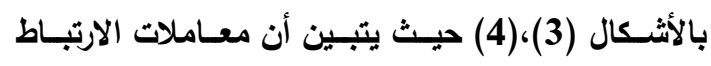
الذاتي ومعاملات الارتباط الجزئي وأثنكال الارتباط الذاتي التي

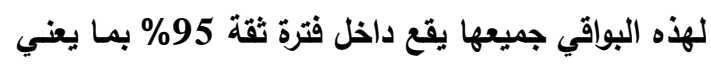
أن الإرتباط الذاتي بين حدود الحد العشوائي غير مغنوي ويالتالي تكون النماذج ملائمة للتقدير. وتسـتذام إختباريـة (ثيل) U-Theil لإختبـار مسدى

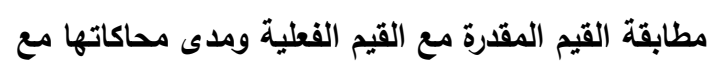




\begin{tabular}{|c|c|c|c|}
\hline & & \multicolumn{2}{|c|}{ جدول رقم (9): المعايير والاختبارات لإختيار أفضل نماذج التتبؤ } \\
\hline \multicolumn{2}{|r|}{ الإختبارات الإحصائية } & \multirow{2}{*}{ نموذج الأريما } & \multirow{2}{*}{ 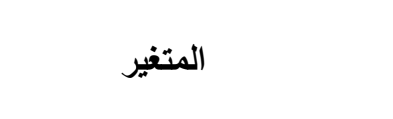 } \\
\hline U.Thiel & Root Mean Square Error & & \\
\hline 0.133 & 46.81 & $(1 ، 1$ ، 1 (2) & كمية صادرات البصل للسعودية \\
\hline 0.319 & 30.93 & $(1 ، 1 ، 2)$ & كمية صادرات البصل لروسيا \\
\hline
\end{tabular}

المصدر: جمعت وحسبث من: بيانات ملحق (1) بالدراسة بإستخدام برنامج 6 E-views

\section{Correlogram of Residuals}

Date: 05/02/17 Time: 22:48

Sample: 20022016

Included observations: 15

Q-statistic probabilities adjusted for 2 ARMA term(s)

\begin{tabular}{|c|c|c|c|c|c|c|c|c|}
\hline \multicolumn{2}{|c|}{ Autocorrelation } & \multicolumn{3}{|c|}{ Partial Correlation } & \multirow{2}{*}{$\frac{A C}{0.177}$} & \multirow{2}{*}{$\frac{\text { PAC }}{0.177}$} & \multirow{2}{*}{$\frac{\text { Q-Stat }}{0.5737}$} & \multirow[t]{2}{*}{ Prob } \\
\hline 1 & $\sqsupseteq \quad$ । & 1 & 1 & 1 & & & & \\
\hline 1 & 1 & 1 & 1 & 2 & -0.021 & -0.054 & 0.5824 & \\
\hline $1 \square$ & 1 & $1 \square$ & 1 & 3 & -0.392 & -0.392 & 3.8446 & 0.050 \\
\hline $1 \square$ & 1 & $1 \square$ & 1 & 4 & -0.324 & -0.231 & 6.2755 & 0.043 \\
\hline 1 & 1 & 1 & 1 & 5 & -0.005 & 0.080 & 6.2763 & 0.099 \\
\hline 1 & 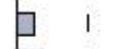 & 1 & 1 & 6 & 0.126 & -0.019 & 6.7295 & 0.151 \\
\hline 1 & b & 1 & 1 & 7 & 0.199 & -0.023 & 7.9929 & 0.157 \\
\hline $1 \square$ & 1 & 1 & 1 & 8 & -0.178 & -0.323 & 9.1466 & 0.166 \\
\hline 1 & I & 1 & 1 & 9 & -0.083 & 0.016 & 9.4392 & 0.223 \\
\hline 1 & 1 & 1 & 1 & 10 & -0.144 & -0.037 & 10.499 & 0.232 \\
\hline 1 & 1 & 4 & 1 & 11 & 0.031 & -0.096 & 10.562 & 0.307 \\
\hline 1 & 1 & $1 \square$ & 1 & 12 & 0.029 & -0.205 & 10.633 & 0.387 \\
\hline
\end{tabular}

\section{Correlogram of Residuals}

Date: $05 / 02 / 17$ Time: $23: 02$

Sample: 20012016

Included observations: 16

Q-statistic probabilities adjusted for 2 ARMA term(s)

\begin{tabular}{|c|c|c|c|c|c|c|c|c|}
\hline \multicolumn{2}{|c|}{ Autocorrelation } & \multicolumn{3}{|c|}{ Partial Correlation } & \multirow{2}{*}{$\frac{A C}{0.049}$} & \multirow{2}{*}{$\begin{array}{l}\text { PAC } \\
0.049\end{array}$} & \multirow{2}{*}{$\frac{\text { Q-Stat }}{0.0462}$} & \multirow[t]{2}{*}{ Prob } \\
\hline । & I & 1 & 1 & 1 & & & & \\
\hline 1 & I & 1 & 1 & 2 & -0.041 & -0.044 & 0.0810 & \\
\hline 1 & I & 1 & 1 & 3 & 0.022 & 0.026 & 0.0915 & 0.762 \\
\hline 1 & 1 & 1 & 1 & 4 & 0.102 & 0.098 & 0.3393 & 0.844 \\
\hline $1 \square$ & I & 1. & 1 & 5 & -0.186 & -0.197 & 1.2450 & 0.74 \\
\hline $1 \square$ & I & $1 \square$ & 1 & 6 & -0.416 & -0.407 & 6.2347 & 0.18 \\
\hline 1 & I & $1 \square$ & 1 & 7 & -0.119 & -0.143 & 6.6878 & 0.245 \\
\hline I & I & 7 & 1 & 8 & 0.090 & 0.084 & 6.9797 & 0.323 \\
\hline $1 \square$ & I & $1 \square$ & 1 & 9 & -0.266 & -0.269 & 9.8891 & 0.19 \\
\hline 1 & 1 & 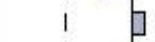 & 1 & 10 & 0.032 & 0.093 & 9.9396 & 0.269 \\
\hline 1 & I & 1 & 1 & 11 & 0.086 & -0.058 & 10.361 & 0.322 \\
\hline । & I & 4 & 1 & 12 & 0.166 & -0.081 & 12.335 & 0.263 \\
\hline
\end{tabular}




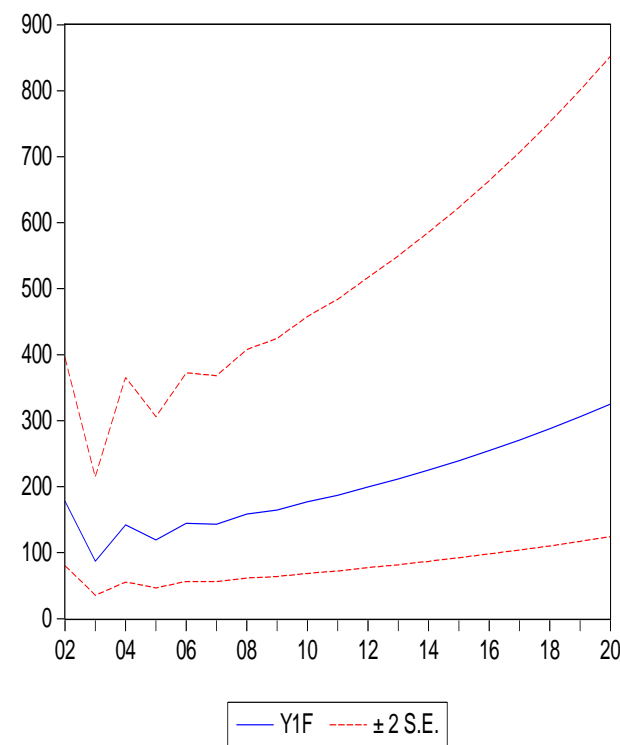

\section{Forecast: Y1F}

Actual: $Y 1$

Forecast sample: 20002020

Adjusted sample: 20022020

Included observations: 15

Root Mean Squared Error $\quad 46.80830$

Mean Absolute Error $\quad 39.62129$

Mean Abs. Percent Error $\quad 38.08626$

Theil Inequality Coefficient $\quad 0.132590$

Bias Proportion $\quad 0.068317$

Variance Proportion $\quad 0.045935$

Covariance Proportion $\quad 0.885748$

الشكل رقم (5) التنبؤ لنموذج كمية صادرات البصل للسعودية

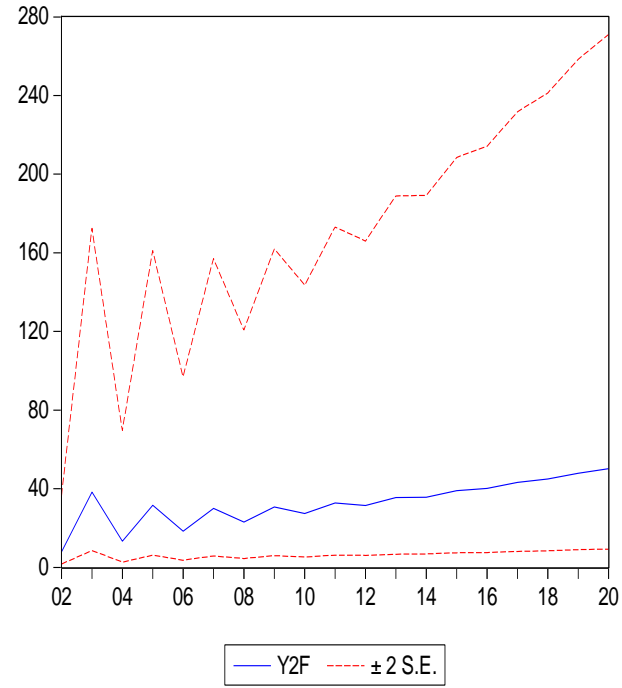

Forecast: Y2F

Actual: $Y 2$

Forecast sample: 20002020

Adjusted sample: 20022020

Included observations: 15

Root Mean Squared Error $\quad 30.93434$

Mean Absolute Error $\quad 21.09463$

Mean Abs. Percent Error $\quad 55.75083$

Theil Inequality Coefficient $\quad 0.369513$

Bias Proportion $\quad 0.231153$

Variance Proportion $\quad 0.460843$

Covariance Proportion $\quad 0.308005$

$$
\text { الشكل رقم (6): التنبؤ لنموذج كمية صادرات البصل لروسيا }
$$

جدول رقم (10) : نتائج التتبؤ بكمية صادرات محصول البصل للسعودية وكمية صادرات محصول البصل لروسيا حتى عام 2020 من خلال أفضل النماذج الايناميكية بإستخدام منهجية أريما بوكس -جينكيز

\begin{tabular}{|c|c|c|c|c|}
\hline نسبة الزيادة عن 2016 & 2020 & 2019 & 2018 & النموذج \\
\hline 25.95 & 325.18 & 305.87 & 287.74 & كمية صادرات البصل للسعودية (ألف طن) \\
\hline 39.73 & 50.14 & 47.88 & 44.91 & كمية صادرات البصل لروسيا (ألف طن) \\
\hline
\end{tabular}

المصدر : جمعت وحسبت من: بيانات ملحق (1) بالاراسة بإستخدام برنامج E-views 6 
10. على عبد العال خليفة ، منا ابراهيم محمود -

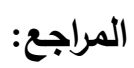

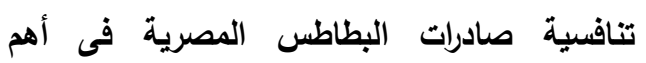

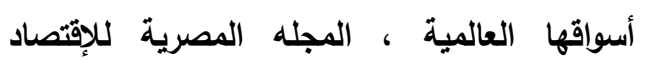

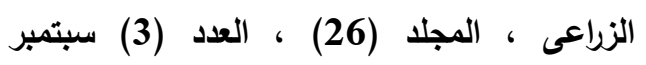

.2016

11. مجدي الثوريجي - الإقتصاد القياسي بين

النظرية والتطبيق ، قسم التجارة الخارجية ، كلية

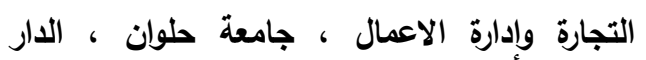

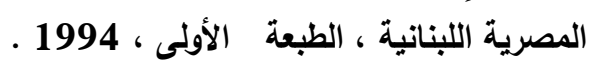

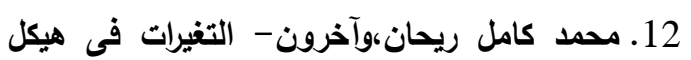

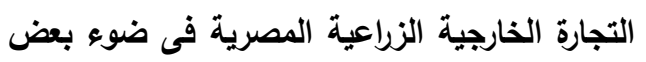

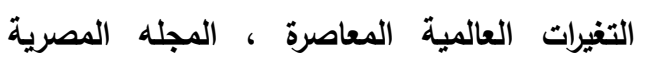

للإقتصاد الزراعى ، المجلد (13) ، العدد الأول

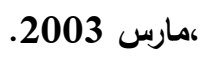

13. محمود عبدالهادي شافعي وآخرون- دراسة

تطبيقية مقارنة للنماذج الاحصائية المستخدمة في

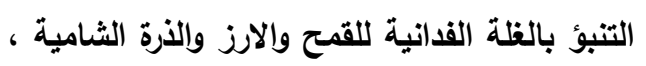

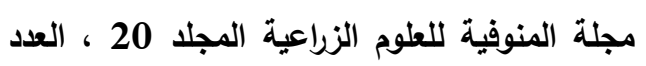

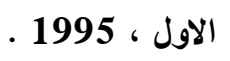

14. هناء شداد محمد عبداللطيف- بعض محددات التاول

الطلب على البطاطس المصرية في أهم أسواقها

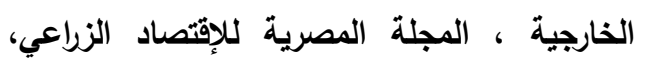

$$
\text { مجلد(17)، العدد (2)، يونيو } 2007 .
$$

15. وزارة الزراعة واستصلاح الأراضس، قطاع الثئون

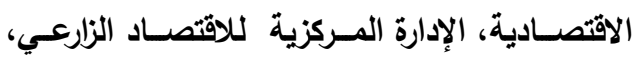

نشرة الإحصاءات الزراعية ، أعداد متفرقة.

16. Henderson M. James and Richard E. quandt, Micro Economic Theory, A mathematical Approach, 3rd, International Student Edition, 1980.

17. Johnston, J., Econometric Methods, 3rd, McGraw-Hill Book Company, New York, 1984.

18. Koutsoyiannis, A., Theory of Econometrics, 2nd. The Macmillan Education L.Td, 1986.

1. الموقع الإكترونسى للجهاز المركزى للتعبئة العامـة www.capmas.gov.eg والإحصاء

2. الموقـع الإكترونـى لقاعـدة بيانـات منظمـة الفـاو www.faostat.org

3. الموقع الإكترونس لقاعدة بيانات التجارة الخارجية

بالأمم المتحدة 3ww.comtrade.com

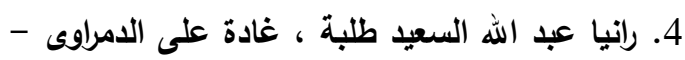

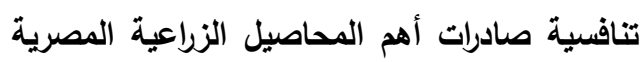

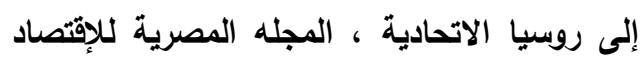

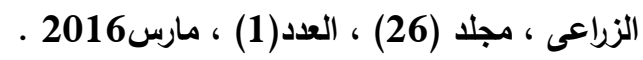

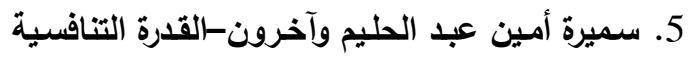
للصادرات المصرية من محصولى الكمون وإلكسبرة ،

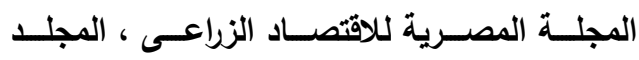
6 العشرون ، العدد الرابع ، ديسمبر 2010.

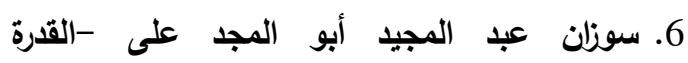

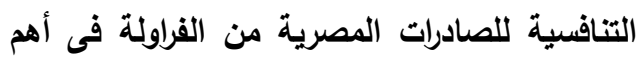
أسواقها الخارجية، المجله المصرية للإقتصاد المادية الزراعى ، مجلد (26) ، العدد(1) ، مارس 2016

7. شحاته عبد المقصود غنيم - قياس القدرة التنافسية لمصر والدول المنافسة لها فى السوق العائ العالمية

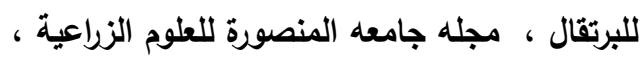

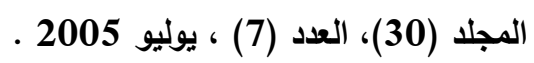

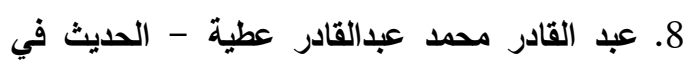

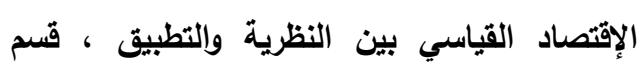

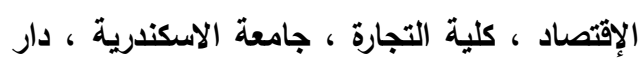

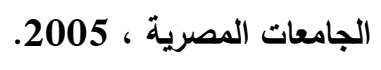

9. عبد الهادى حمزة وآخرون سمؤشر عدم الإستقرار

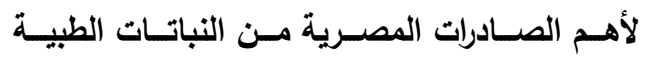

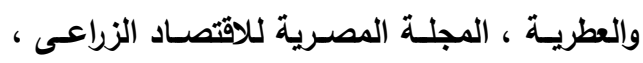

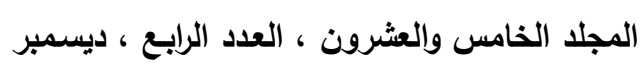
.2015 
الملاحق

ملحق (1) : قيمة الميزان التجارى الكلى والزراعى المصرى خلال الفترة (2000-2016) (القيمة: مليون دولار -الكمية : ألف طن)

\begin{tabular}{|c|c|c|c|c|c|c|c|c|}
\hline \multicolumn{2}{|c|}{ الصادرات الكلية للبصل } & \multicolumn{3}{|c|}{ التجارة الخارجية الزراعية } & \multicolumn{3}{|c|}{ التجارة الخارجية الكلية } & \multirow[b]{2}{*}{ 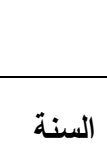 } \\
\hline كمية & قيمة & 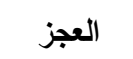 & الواردات & الصادرات & العجز العز & الواردات & الصادرات & \\
\hline 157.58 & 26.98 & 1449.6 & 1958.3 & 508.7 & 9279 & 13978 & 4699 & 2000 \\
\hline 173.72 & 24.75 & 1391.7 & 1921.8 & 530.2 & 8585 & 12728 & 4143 & 2001 \\
\hline 304.03 & 39.29 & 1484.8 & 2155.9 & 671.0 & 7818 & 12496 & 4678 & 2002 \\
\hline 332.35 & 50.73 & 907.7 & 1684.0 & 776.3 & 4736 & 10902 & 6166 & 2003 \\
\hline 342.33 & 58.46 & 600.8 & 1705.4 & 1104.6 & 5159 & 12837 & 7678 & 2004 \\
\hline 318.24 & 56.84 & 1490.0 & 2407.9 & 917.9 & 9165 & 19808 & 10643 & 2005 \\
\hline 220.74 & 46.15 & 1414.3 & 2269.4 & 855.2 & 6871 & 20586 & 13715 & 2006 \\
\hline 217.88 & 70.04 & 2444.2 & 3646.6 & 1202.5 & 10874 & 27054 & 16180 & 2007 \\
\hline 270.06 & 134.60 & 2729.7 & 4819.4 & 2089.7 & 26535 & 52793 & 26258 & 2008 \\
\hline 255.74 & 203.34 & 1422.3 & 4389.9 & 2967.6 & 20752 & 44958 & 24206 & 2009 \\
\hline 512.33 & 227.21 & 2500.4 & 5631.8 & 3131.4 & 25748 & 53107 & 27359 & 2010 \\
\hline 490.82 & 215.38 & 5185.2 & 8210.9 & 3025.7 & 30673 & 62223 & 31550 & 2011 \\
\hline 347.72 & 154.23 & 6121.9 & 8805.5 & 2683.7 & 41838 & 71102 & 29264 & 2012 \\
\hline 371.68 & 201.76 & 2265.8 & 5132.8 & 2867.0 & 37487 & 66183 & 28696 & 2013 \\
\hline 366.94 & 168.53 & 1210.6 & 4164.6 & 2954.0 & 46296 & 73838 & 27542 & 2014 \\
\hline 1219.07 & 263.46 & 1247.8 & 4100.0 & 2852.2 & 53032 & 74372 & 21340 & 2015 \\
\hline 515.03 & 193.87 & 1164.0 & 3839.9 & 2675.9 & 37608 & 59730 & 22122 & 2016 \\
\hline $\mathbf{3 7 7 . 4 3}$ & 125.62 & 2060.6 & 3932.0 & 1871.4 & 22497 & 40511 & 18014 & المتوسط \\
\hline
\end{tabular}

المصدر : جمعت وحسبت من : الموقع الإكترونى للجهاز المركزى للتعبئة العامة والإحصاء:Www.capmas.gov.eg 
ملحق (2) : الميزان الزراعى العالمى بالمليون دولار خلال الفترة (2000-2015)

\begin{tabular}{|c|c|c|c|c|}
\hline إلجالى قيمة الصادرات & الميزان الزراعى العالمى & قيمه الواردات الزراعية & قيمه الصادرات الزراعية & السنة السنة \\
\hline 781.9 & -22200 & 433180 & 410980 & 2000 \\
\hline 870.4 & -27480 & 441840 & 414360 & 2001 \\
\hline 967.0 & -22590 & 465260 & 442670 & 2002 \\
\hline 1290.4 & -26450 & 551660 & 525210 & 2003 \\
\hline 1361.7 & -30990 & 638320 & 607330 & 2004 \\
\hline 1419.1 & -26358 & 679893 & 653535 & 2005 \\
\hline 1676.8 & -32496 & 753968 & 721472 & 2006 \\
\hline 2081.7 & -39975 & 913262 & 873287 & 2007 \\
\hline 2206.1 & -51013 & 1118566 & 1067553 & 2008 \\
\hline 2258.9 & -37096 & 988056 & 950960 & 2009 \\
\hline 2978.6 & -22630 & 1107372 & 1084742 & 2010 \\
\hline 2891.7 & -36766 & 1357005 & 1320239 & 2011 \\
\hline 2417.0 & -32188 & 1369859 & 1337671 & 2012 \\
\hline 3265.8 & -32785 & 1429348 & 1396563 & 2013 \\
\hline 3073.93 & -33755 & 1456519 & 1422764 & 2014 \\
\hline 3317.24 & -23588 & 1491882 & 1468294 & 2015 \\
\hline 3246.72 & - & - & 1491312 & 2016 \\
\hline 2123.8 & -31148 & 949749 & 952291 & المتوسط \\
\hline
\end{tabular}

المصدر : جمعت وحسبت من : الموقع الإكترونى لمنظمة الأغذية والزراعة العالمية: 
ملحق (3) : متغيرات دالة الطلب الخارجى للبصل المصرى فى الأسواق الخارجية خلال الفترة (2000-2016)

\begin{tabular}{|c|c|c|c|c|c|c|c|c|c|}
\hline سعرف & اللتصدير & التصدير & الكمية المصدرة & البصل الهدرة من الكمية & التصدير & الاستهلاك & الإحلى الإتاج & إلجمالى البصل & $\overline{7}$ \\
\hline جنيه/دولار & دولار/طن & دولار/طن & ألف طن & ألف طن & دولار/طن & ألف طن & ألف طن & ألف طن & \\
\hline 3.472 & 202 & 142 & 668.7 & 246.8 & 171.2 & 1147 & 1279 & 157.6 & 2000 \\
\hline 3.973 & 213 & 172 & 704.4 & 383.6 & 142.5 & 844 & 1010 & 173.7 & 2001 \\
\hline 4.500 & 238 & 137 & 759.3 & 549.2 & 129.2 & 983 & 1276 & 304.0 & 2002 \\
\hline 5.851 & 272 & 165 & 887.1 & 713.1 & 152.6 & 928 & 1248 & 332.4 & 2003 \\
\hline 6.196 & 296 & 183 & 881.7 & 909.2 & 170.8 & 1289 & 1619 & 342.3 & 2004 \\
\hline 5.779 & 238 & 170 & 908.1 & 901.6 & 178.6 & 1635 & 1936 & 318.2 & 2005 \\
\hline 5.733 & 337 & 160 & 911.7 & 1414.6 & 209.1 & 1406 & 1609 & 220.7 & 2006 \\
\hline 5.635 & 445 & 293 & 962.0 & 899.3 & 321.5 & 1373 & 1574 & 217.9 & 2007 \\
\hline 5.433 & 362 & 214 & 1169.2 & 1546.8 & 498.4 & 1700 & 1961 & 270.1 & 2008 \\
\hline 5.545 & 362 & 262 & 1081.0 & 1812.4 & 795.1 & 2201 & 2436 & 255.7 & 2009 \\
\hline 5.622 & 418 & 375 & 1509.7 & 1241.4 & 443.5 & 1894 & 2406 & 512.3 & 2010 \\
\hline 5.933 & 390 & 333 & 1640.8 & 1110.1 & 438.8 & 2000 & 2491 & 490.8 & 2011 \\
\hline 6.056 & 347 & 193 & 1417.3 & 1527.8 & 443.5 & 2046 & 2383 & 347.7 & 2012 \\
\hline 6.870 & 412 & 394 & 1637.2 & 1525.4 & 542.8 & 1485 & 2084 & 371.7 & 2013 \\
\hline 7.078 & 381 & 254 & 1604.5 & 1267.3 & 459.3 & 2350 & 2717 & 366.9 & 2014 \\
\hline 7.726 & 351 & 409 & 1573.0 & 1048.5 & 216.1 & 2544 & 3095 & 1219.1 & 2015 \\
\hline 10.187 & 385 & 208 & 1606.6 & 1837.2 & 376.4 & 2253 & 2794 & 515.0 & 2016 \\
\hline 5.976 & 332 & 239 & 1171.9 & 1113.8 & 334.7 & 1652 & 1995 & 377.4 & متوسط \\
\hline
\end{tabular}

المصدر : جمعت وحسبت من :

1-الموقع الإكترونى للجهاز المركزى للتعبئة العامة والإحصاء: 


\title{
AN ABILITY COMPETITIVE FOR EGYPTIAN ONION EXPORTS TO THE MOST IMPORTANT INTERNATIONAL MARKETS AND ITS FUTURE FORECASTING
}

\author{
E. El-Sherbini \\ dremad222@yahoo.com
}

Researcher - Agricultural Economics Research Institute

\begin{abstract}
The Foreign trade in the globalization and the liberalization of international trade played an important role in economic development, especially the total exports, which made it necessary to increase the competitiveness of total agricultural exports to reduce the trade and agricultural gap. The study aims at determining the most important factors affecting in the Egyptian onions external demand of in the most important international markets. The research relied on the method of statistical analysis, descriptive and quantitative analysis, time series analysis, simple regression, multiple regression, stepwise, the value of $R 2, t, F$, and using some of the competitive measures such as (market share index, market penetration rate, price index, geographic concentration index "Gini Hirschman").
\end{abstract}

The results of the study were:

1-The competitive index for the comparative advantage of Egyptian onion exports showed an increase in the competitiveness of onion crop in foreign markets during the study period.

2-Increasing the penetration rates of onion crop to the Arab countries were about $57.8 \%$ in Saudi Arabia and $34.9 \%$ in Kuwait. However, it is very low in the EU countries, about $2.1 \%$ in the UK and $1.5 \%$ in Romania, $1.4 \%$ in Italy, searching the reasons for the decline, try to open new markets, benefit from the experiences of the competitive countries, in the export of onion crop.

3-Availability of sufficient data for exporters, on the external market, encourage studies based on the study of external demand, for agricultural exports of the most important Egyptian export crops

4- The demand for Egyptian onion to Saudi market depends on the total domestic production of onions, total domestic consumption of onions, amount of Egyptian exports of onions for the Netherlands market, the export price of Indian onions, where it was found that these variables explain about $85.5 \%$ of the changes in the amount of Egyptian exports of onions, for the Saudi market. Where the demand for Egyptian onion to Russian market depends on the export price of the Egyptian onion, the export price of Indian onions, where it was found that these variables explain about $72.6 \%$ of the changes in the amount of Egyptian exports of onions for the Russian market.

5- Putting policies to increasing onion production, to ensure increased quantity exported, and thus increase the value of exports.

6- The results of the forecasting of the quantity of onion exports to Saudi Arabia and to Russia, using the Box-Jenkins until 2020, indicate that the quantity of exports to Saudi Arabia expected to reach about 325.18 thousand tons by 2020, it was found that an increase in the quantity of onion exports to Russia expected to reach about 50.14 thousand tons by 2020.

Key words: Competitive, Market share indictor, Market penetration indictor, Price ratio index, Geographic concentration indictor, Gini Hirschman, Revealed comparative advantage indictor, Instability coefficient, External demand determinants, Forecasting, ARIMA Model.

$$
\begin{aligned}
& \text { أسماء السادة المحكمين } \\
& \text { أ.د/ محمد على شطـ كلية الزراعة - جامعة المنصورة أ.د/ إبراهيم صديق على كلية الزراعة - جامعة المنوفية }
\end{aligned}
$$


An ability Competitive for Egyptian Onion Exports to the Most Important ........... 